\title{
RELATOS DE PESQUISAS \\ O DESEMPENHO INOVADOR DE AGÊNCIAS DE PUBLICIDADE E SUA RELAÇÃO COM A GESTÃO DO CONHECIMENTO E CONDIÇÕES ORGANIZACIONAIS DE INOVATIVIDADE E CRIATIVIDADE
}

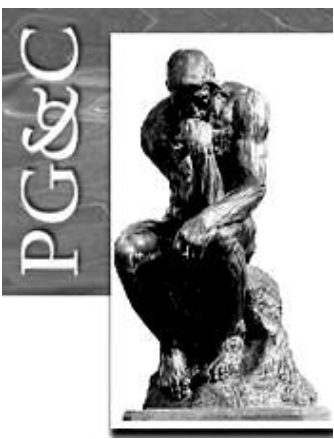

\author{
Cicero Aparecido Bezerra \\ Doutor em Engenharia de Produção pela Universidade Federal de Santa \\ Catarina, Brasil. Professor da Universidade Federal do Paraná, Brasil. \\ E-mail: cicero.bezerra@ufpr.br \\ André José Ribeiro Guimarães \\ Mestre em Ciência, Gestão e Tecnologia da Informação pela Universidade \\ Federal do Paraná, Brasil. Professor da Universidade Federal do Paraná, \\ Brasil. \\ E-mail: andrejrg@gmail.com
}

\begin{abstract}
Resumo
A presente pesquisa objetiva identificar a existência de associações entre as condições habilitadoras da inovação, os aspectos capacitadores da gestão do conhecimento, as condições ambientais para a criatividade organizacional e o desempenho inovador das empresas de publicidade. Trata-se de um trabalho situado na fronteira dos estudos descritivos e exploratórios, que emprega métodos quantitativos bi e multivariados para tornar explícitas as conexões buscadas. Os resultados evidenciam relações diretamente proporcionais entre os aspectos capacitadores da gestão do conhecimento, as condições habilitadoras da inovação e da criatividade e o desempenho inovador das empresas pesquisadas. Conclui com a consolidação de modelos distintos que se integram ao explicarem o desempenho inovador, a partir dos elementos de gestão do conhecimento, criatividade e inovatividade organizacionais.
\end{abstract}

Palavras-chave: Gestão do conhecimento. Inovatividade. Criatividade. Desempenho inovador. Agências de publicidade.

\section{THE INNOVATIVE PERFORMANCE IN THE ADVERTISING AGENCIES AND ITS RELATIONSHIP WITH KNOWLEDGE MANAGEMENT AND CONDITIONS OF ORGANIZATIONAL INNOVATIVENESS AND CREATIVITY}

\begin{abstract}
This research identifies the existence of associations between the enabling conditions for innovation, enablers aspects of knowledge management, environmental conditions for organizational creativity and the innovation performance of advertising companies. This research is situated on the border of descriptive and exploratory studies, employing quantitative methods bi and multivariate to make explicit the connections. The results show directly proportional relationship between aspects of knowledge management, the enabling conditions for innovation and creativity and the innovation performance of companies surveyed. It concludes with the consolidation of different models that integrate to explain the innovative performance from the elements of knowledge management, creativity and organizational innovativeness.
\end{abstract}

Keywords: Knowledge management. Innovativeness. Creativity. Innovative performance. Advertising agencies.

Perspectivas em Gestão \& Conhecimento, João Pessoa, v. 7, n. 1, p. 70-97, jan./jun. 2017. DOI: http://dx.doi.org/10.21714/2236-417X2017v7n1p70

http://periodicos.ufpb.br/ojs2/index.php/pgc. ISSN: 2236-417X. Publicação sob Licença (cc) EY-NC-ND 


\section{INTRODUÇÃO}

O mercado publicitário tem demonstrado expressivo vigor econômico, visto que os investimentos mundiais com publicidade cresceram 3,5\% em 2012, e a previsão de aumento para 2013 é da ordem de 3,9\%, sendo que, para 2015, projeção de aumento é 5,6\% (ZENITHOPTIMEDIA, 2013). Neste cenário, o Brasil ocupa posição de destaque: encontra-se classificado na sexta posição no ranking dos países que mais investiram em publicidade no mundo, com um montante de aproximadamente 18 bilhões de dólares, sendo que a previsão para 2015 é de investimentos na ordem de 24 bilhões de dólares, ultrapassando a Inglaterra (ZENITHOPTIMEDIA, 2013). Mesmo sendo um mercado em expansão, e talvez por esta razão, este segmento vem enfrentando forte concorrência - fazendo como que as empresas busquem "fortalecer sua marca por meio de ações inovadoras" (TARSITANO, 2008, p.180). Neste sentido, a inovação, como estratégia de competitividade, tem sido recorrentemente associada à gestão do conhecimento (DALKIR, 2005). Especificamente, em relação ao mercado publicitário, o desenvolvimento contínuo do conhecimento é fundamental para a sobrevivência das empresas (EWING; WEST, 2000). Mesma importância é dada à criatividade, visto que o mercado das empresas de publicidade vive da criatividade, que é o elemento mais importante para que as organizações deste segmento atinjam o sucesso (EL-MURAD; WEST, 2004). Ainda assim, muitos gestores, com a intenção de beneficiar seus negócios, acabam prejudicando as condições propícias para o desenvolvimento da atividade criativa, na medida em que promovem pressões para maximizar a produtividade, excesso de controle e, principalmente, falta de apoio (AMABILE, 1998).

Em que pese a importância dos elementos organizacionais de inovação, conhecimento e criatividade neste segmento econômico, estudos científicos têm relevado a associação destes elementos junto às organizações de publicidade. A despeito da importância, a criatividade é o aspecto menos científico dos processos destas empresas (EL-MURAD; WEST, 2004). Em relação ao desempenho organizacional nenhum estudo tem examinado se a criatividade melhora o desempenho da empresa (GONG; ZHOU; CHANG, 2013). Quanto à gestão do conhecimento, é necessário e oportuno que pesquisadores pensem em termos interdisciplinares, com foco na publicidade e a efetiva cadeia de conhecimento (ARORA, 2012). A carência de estudos, no Brasil, que envolvem agências de publicidade, relacionadas tanto a gestão do conhecimento e inovação, como a criatividade, é particularmente notável. Em uma busca realizada em 15 de dezembro de 2014 nos periódicos da Coordenação de Aperfeiçoamento de Pessoal de Nível Superior (CAPES), da área de avaliação de Administração, Ciências Contábeis e Turismo, pelos termos 'conhecimento', 'inovação' e 'criatividade', associados ao termo 'publicidade' no campo referente ao assunto dos artigos, traz apenas cinco registros, sendo que nenhum deles aborda questões de desempenho organizacionais.

Neste contexto, o presente estudo tem como objetivo identificar a percepção com que as condições habilitadoras da inovação, os aspectos capacitadores da gestão do conhecimento e, as condições ambientais para a criatividade organizacional, encontram-se associadas ao desempenho inovador das empresas de publicidade. A pesquisa foi realizada por meio de survey aplicada em agências vinculadas ao Sindicato das Agências de Propaganda do Paraná (SINAPRO/PR) e Conselho Executivo das Normas Padrão (CENP), em atividade no Paraná, tendo os resultados sido analisados por métodos quantitativos bi e multi variados.

\section{REFERENCIAL TEÓRICO}

Esta seção apresenta os principais conceitos abordados na pesquisa. Ressalta-se que não se pretende esgotar os assuntos, mas sim apresentar as definições mínimas necessárias para o entendimento dos termos no contexto do estudo.

Perspectivas em Gestão \& Conhecimento, João Pessoa, v. 7, n. 1, p. 70-97, jan./jun. 2017. 


\subsection{Gestão do conhecimento}

Antes de abordar os conceitos de Gestão do Conhecimento (GC), há que se estabelecer breve reflexão sobre o termo 'conhecimento'. Ainda que não se possam estabelecer os elementos que caracterizam o conhecimento como consenso, muitos deles são recorrentemente empregados. As principais características do conhecimento estão atreladas a (1) crenças e compromissos, ou seja, depende das experiências do indivíduo, (2) ação e, (3) é específico ao contexto e relacional (NONAKA; TAKEUCHI, 1997). Além disto, o conhecimento apresenta características adicionais: (1) a dificuldade em expressá-lo, visto que é dependente das experiências dos indivíduos, (2) a orientação para a ação, (3) o fato de ser sustentado por regras atreladas ao resultado das ações e, (4) o fato de estar em constante mutação (SVEIBY, 1998). Também é possível identificar algumas propriedades: (1) produto da mente humana; (2) exige reflexão, síntese e contexto; (3) é difícil de ser estruturado; (4) é difícil de ser capturado por máquinas; (5) é frequentemente tácito e; (6) é de difícil transferência (DAVENPORT, 1998).

O conhecimento é um ativo que se torna obsoleto rapidamente, o que obriga as organizações a 'esquecerem' o conhecimento antigo e a obterem novos conhecimentos e competências de forma contínua - neste sentido, o papel da GC é tornar disponível para a organização o conhecimento certo, na hora certa e no lugar certo (CANTNER; JOEL; SCHMIDT, 2009). Porém, há que se levarem em consideração outras definições:

- Entendimento e foco na construção, renovação e aplicação do conhecimento de forma sistemática, deliberada e explícita (WIIG, 1997);

- Processo de criação, validação, apresentação, distribuição e aplicação do conhecimento (BHATT, 2001);

- Processo pelo qual a organização gera riqueza, a partir do seu conhecimento ou capital intelectual (BUKOVITZ; WILLIAMS, 2002);

- Coordenação deliberada e sistemática de pessoas, tecnologias, processos e estrutura de uma organização com o objetivo de adicionar valor por meio do reuso e da inovação (DALKIR, 2005).

Conceitualmente, Saeger (2016, p. 273), citando a obra 'Da informação à auditoria de conhecimento: a base para a inteligência organizacional' de Emeide Nóbrega Duarte, Rosilene Agapito da Silva Llarena e Suzana de Lucena Lira, define a GC como "a gestão do ambiente que, a partir de condições capacitadoras, irá favorecer a criação e o compartilhamento do conhecimento". Segundo o Ministério do Planejamento, Orçamento e Gestão (BRASIL, 2013, p. 6), trata-se de "um princípio gerencial que permite ampliar informação, conhecimento, experiência e intuição nas organizações a fim de gerar valor (resultados para a organização)". De modo geral, a GC "promove o crescimento do capital intelectual, que por sua vez agrega valor a produtos e serviços" (WILLERDING; KRAUSE; LAPOLLI, 2016, p. 144), integrando informação, "processos, pessoas e recursos" (VARELA; BARBOSA; FARIAS, 2015, p. 51). Em uma perspectiva menos abrangente, é possível afirmar que a Gestão do Conhecimento "visa a sustentação do processo de decisão nos diversos níveis da organização" (FIALHO, 2014, p. 20).

Trata-se de uma área que incorpora várias abordagens gerenciais como gestão e ciência da informação, gestão de recursos humanos, capital intelectual, aprendizagem organizacional, métricas e mensuração de ativos intangíveis, ambiente organizacional, e a criação de conhecimento e gestão da inovação (ALVARENGA NETO, 2008). O surgimento desta área de estudos iniciou sua consolidação nos anos entre 1986 e 1989 onde vários relatos de pesquisa abordavam preocupações nos processos de gerenciamento do conhecimento organizacional (WIIG, 1997). Para Sveiby (2001) o termo 'gestão do conhecimento' foi

Perspectivas em Gestão \& Conhecimento, João Pessoa, v. 7, n. 1, p. 70-97, jan./jun. 2017. 
apresentado em 1986 pela primeira vez justamente por Karl Wiig, quando da publicação do primeiro artigo que continha estas palavras no título "Knowledge Management: An Introduction". No Brasil, esta área tem gerado estudos interdisciplinares surgidos da intersecção da Administração e Ciência da Informação (COSTA, et al., 2013).

As pesquisas têm mostrado que a GC tem sido abordada das mais variadas (e segmentadas) maneiras (GONZALEZ; MARTINS, 2015). Existem estudos que focam nos aspectos tecnológicos necessários à captura, processamento, armazenamento e disseminação do conhecimento (CHADHA; SAINI, 2014; NAILA, et al., 2014; NANDITA, 2013); estruturas organizacionais necessárias à formação e utilização do conhecimento (PRADO; FISCHER, 2013; SAINI, 2013; VON KROGH; NONAKA; RECHSTEINER, 2012); processos específicos do conhecimento (HAWKINS; NISSEN; RENDON, 2014; HAYES; WALSHAM, 2005; MCIVER, et al., 2013); cultura organizacional necessária ao uso do conhecimento como recurso (CHRISTOPHER; TANWAR, 2012; PUGNA; BOLDEANU, 2014; TAYLOR, 2013). Além disto, estudos mais pragmáticos têm abordado, cada vez mais, específicas práticas empresariais capazes de potencializar a GC (BEZERRA; BARBOSA; ESPEJO, 2013; MCFADDEN, et al., 2014; BEZERRA; GUIMARÃES, 2014). Neste sentido, Gold, Malhotra e Segars (2001) apresentam um modelo cuja abordagem integra muitos dos elementos estudados de maneira segmentada em GC, que conduzem à efetividade organizacional, conforme mostrado na Figura 1:

Figura 1 - Gestão do conhecimento e efetividade organizacional

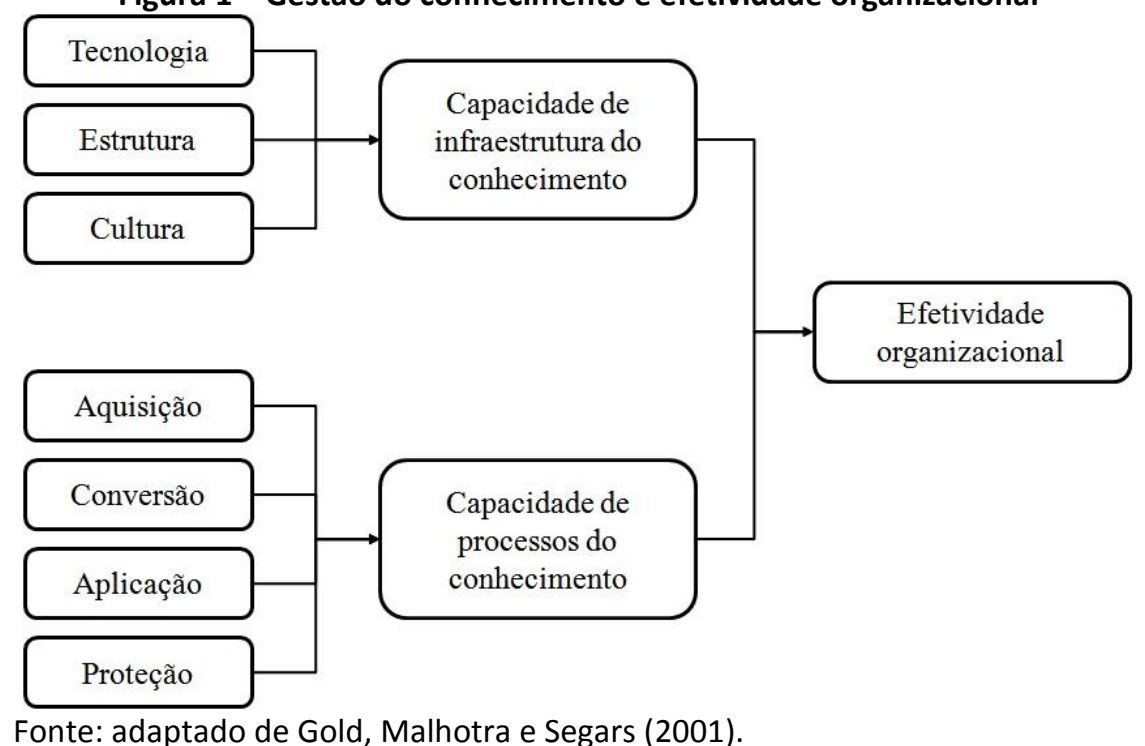

As pesquisas têm mostrado que a GC tem sido abordada das mais variadas (e De acordo com o modelo apresentado, a tecnologia (recursos tecnológicos disponíveis na empresa), a estrutura (conjunto de normas e mecanismos organizacionais) e, a cultura (contexto de compartilhamento) são os elementos que formam a infraestrutura do conhecimento que, em conjunto com os processos de aquisição, conversão, aplicação e proteção do conhecimento, sintetizados como a capacidade de processos do conhecimento, levam à efetividade organizacional (GOLD; MALHOTRA; SEGARS, 2001).

A GC tem sido recorrentemente associada à inovação (BEZERRA; GUIMARÃES, 2014). Especificamente, é possível encontrar estudos que a abordam como meio para incrementar a capacidade de reação das organizações às demandas de inovação (CHRISTOPHER; TANWAR, 2012) e, até mesmo, a tomando como complementaridade ao termo 'inovação' (CAMELOORDAZ, et al., 2011).

Perspectivas em Gestão \& Conhecimento, João Pessoa, v. 7, n. 1, p. 70-97, jan./jun. 2017. 


\subsection{Inovação e inovatividade}

Várias definições convergem para o fato de que a inovação é um dos elementos necessários à obtenção de vantagem competitiva sustentável para as organizações (REJEB, et al., 2008). Especificamente, abrange cinco aspectos, a saber: (1) introdução de um novo bem (seja ele, produto ou serviço), desconhecido pelos consumidores, ou de uma qualidade nova do bem; (2) introdução de um novo método de produção, que não tenha sido anteriormente testado no meio industrial em questão; (3) abertura de um mercado novo, onde o ramo da indústria em questão não tenha sido anteriormente explorado; (4) conquista de novas fontes de fornecedores de matéria prima ou de bens semimanufaturados, sejam estes existentes, ou a serem criados; (5) estabelecimento de uma nova organização para o negócio, seja criando ou rompendo um monopólio (SCHUMPETER, 1934).

A compreensão da inovação, enquanto processo organizacional apoia-se em vários modelos - cada qual com perspectivas distintas. É possível expressá-la linearmente, sendo tanto originada por pesquisa básica, chegando ao mercado (por meio de pesquisa aplicada, desenvolvimento e engenharia), como por uma necessidade de mercado que demanda geração e desenvolvimento de ideias e engenharia para atendê-la (CARVALHO; REIS; CAVALCANTE, 2011). Possíveis limitações de modelos lineares podem ser supridas por estruturas que expressem interações cíclicas em cadeia (STAL, 2007).

De maneira geral, os resultados em inovação podem ser sentidos, nas empresas, tanto em aspectos voltados em melhorias nos processos organizacionais internos (REMNELANDWIKHAMN; WIKHAMN, 2011), processos produtivos (ABECASSIS-MOEDAS; BENGHOZI, 2012), como em lançamentos de produtos e serviços considerados inovadores pelo mercado (AUTANT-BERNARD, et al., 2010; BROCKMAN; JONES; BECHERER, 2012).

Enquanto o termo 'inovação' é recorrentemente relacionado a resultados inovadores (AUTANT-BERNARD, et al., 2010), 'inovatividade' encontra-se associado às condições organizacionais que capacitam as empresas a inovarem (DIBRELL; CRAIG; HANSEN, 2011; DOTZEL; SHANKAR; BERRY, 2013). Neste sentido, o impacto do comportamento inovador (inovatividade) em produzir inovações pode ser representado pela Figura 2:

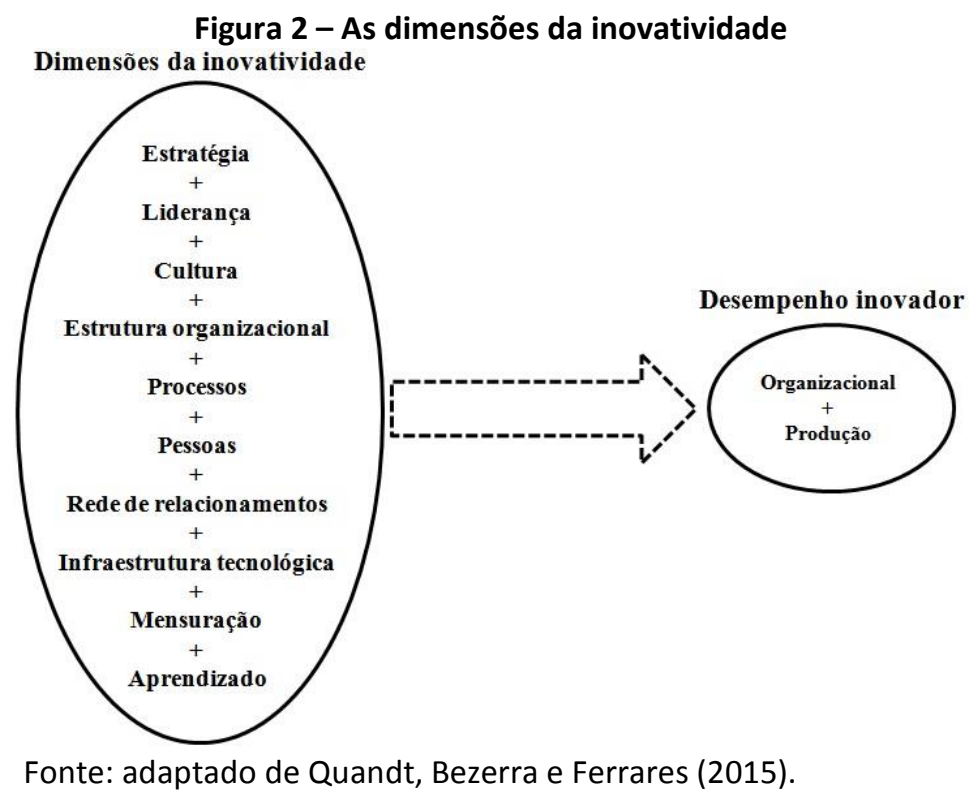

Perspectivas em Gestão \& Conhecimento, João Pessoa, v. 7, n. 1, p. 70-97, jan./jun. 2017. 
Os elementos que compõem o modelo são assim definidos:

- Estratégia: prioridade estratégica refletida em ações específicas de inovação (PRESTER; BOZAC, 2012);

- Liderança: capacidade dos líderes em estimular o comportamento inovador (DENTI; HEMLIN, 2012);

- Cultura: conjunto de crenças, normas e valores organizacionais que dão suporte ao desempenho inovador (BROCKMAN; JONES; BECHERER, 2012; RUBERA; KIRCA, 2012);

- Estrutura organizacional: divisão, organização e coordenação de unidades administrativas, sejam formais ou informais, que conduzem à inovação (PRESTER; BOZAC, 2012; UZKURT, et al., 2012);

- Processos: implementação de planos de identificação de oportunidades alinhados e elementos tecnológicos (SHEU; LEE, 2011);

- Recursos humanos: a gestão da capacidade cognitiva das pessoas está diretamente relacionada com a capacidade inovativa das organizações (BORNAY-BARRACHINA, et al., 2012);

- Relacionamentos: a abertura da empresa às alianças, redes ou outras formas de ligação com seu entorno sistêmico, explica muito do desempenho inovador (CLAUß, 2012);

- Infraestrutura tecnológica: a sustentação tecnológica aos processos inovadores permite redução de riscos (DOTZEL; SHANKAR; BERRY, 2013), falhas e tempo de desenvolvimento (ABECASSIS-MOEDAS; BENGHOZI, 2012);

- Mensuração: capacidade da organização em medir continuamente seus ativos inovadores, quer sejam entradas, processos ou saídas. Processos de mensuração são de fundamental importância neste contexto (AUTANTBERNARD, et al., 2010; RAO, 2010);

- Aprendizagem: sistemas de ações, atores, símbolos e processos que habilitam uma organização a transformação informação em conhecimento (MOHANTY; $K A R, 2012)$ que, por sua vez, se encontra intimamente ligado à inovação (BROCKMAN; JONES; BECHERER, 2012; RUBERA; KIRCA, 2012).

É importante destacar que o termo 'inovatividade' tem sido empregado com significados distintos. Enquanto Rogers (1983), Dotzel, Shnakar e Berry (2013) utilizam o termo como sendo à disposição das empresas (ou pessoas) em adotar novas ideias (ou produtos/serviços), autores como Cepeda-Carrion, Cegarra-Navarro e Jimenez-Jimenez (2012), Dibrell, Craig e Hansen (2011) o associam a condições organizacionais que levam as organizações a inovar. Para este estudo, toma-se 'inovatividade' como sendo "dimensões organizacionais que envolvem a gestão eficaz dos fluxos de conhecimento interno e externo e dos ativos tangíveis e intangíveis que sustentam a capacidade da empresa para inovar de forma contínua e duradoura" (QUANDT; BEZERRA; FERRARESI, 2015, p. 875).

Seja como for, além destes elementos na estruturação das condições organizacionais que levam à inovação, a literatura especializada é abundante em associar o papel da criatividade neste contexto (CLAUß, 2012; DENTI; HEMLIN, 2012).

\subsection{Criatividade}

Os conceitos de criatividade e inovação se distinguem pelo fato de criatividade ser o componente de geração de ideias da inovação, e a inovação como o processo que abrange o

Perspectivas em Gestão \& Conhecimento, João Pessoa, v. 7, n. 1, p. 70-97, jan./jun. 2017. 
propósito e a aplicação das novas ideias (WEST; FARR, 1990). A primeira análise sobre o conceito de criatividade foi feita em 1950 pelo psicólogo e pesquisador Joy Paul Guilford (SOHN; JUNG, 2010), que definiu criatividade como a habilidade de um indivíduo em apresentar comportamento divergente ao apresentar soluções alternativas para um problema (GUILFORD, 1950).

Durante décadas, as pesquisas sobre criatividade focaram no indivíduo, pouco acrescentando ao ambiente social e, por consequência, na inovação (AMABILE, 1996). Posteriormente, a mesma autora afirma que a criatividade não pode ser caracterizada somente pela geração de ideias - estas devem ser apropriadas, úteis e factíveis, voltadas a um objetivo pré-estabelecido, gerando valor à organização (AMABILE, 1998). Para incrementar a inovação, muitas das iniciativas tomadas visam valorizar a criatividade individual e organizacional (SOHN; JUNG, 2010; MATHISEN; EINARSEN, 2004).

Porém, a literatura especializada tem apresentado resultados díspares quanto à forma de empregar a criatividade como elemento de desempenho organizacional:

- Muitos gestores não sabem como administrar os componentes criativos da inovação e, erroneamente, acreditam que o estabelecimento de estruturas e processos pode atrapalhar a criatividade; quando na verdade, uma estrutura estabelecida de maneira adequada pode contribuir para o seu aumento (DAVILA; EPSTEIN; SHELTON, 2007);

- Por outro lado, há um falso conceito de que as organizações criativas não podem ser disciplinadas em seus processos (CARLSON; WILMOT, 2006);

- Além disto, há que se atentar para o fato de que processos sistemáticos e estruturas não necessariamente levam à criatividade (BRATTSTROM; LOFSTEN; RICHTNÉR, 2012);

- Envolvendo especificamente criatividade e inovação, a potencial tensão entre a criação e a implementação de novas ideias podem requerer diferentes, senão opostas, condições, visto que a criação é baseada em processos divergentes, enquanto que a implementação requer processos convergentes (GONG; ZHOU; CHANG, 2013);

- A diversidade de estudos sobre a criatividade nas organizações indica que a natureza dinâmica das empresas pode tanto ser benéfica, quanto prejudicial à criatividade - os modelos que envolvem a criatividade no contexto empresarial ainda não expressam todo o cenário (GILSON, et al., 2013).

Seja como for, não se pode negar a importância da criatividade, em um primeiro momento, diretamente na inovação e, como resultado, na competitividade das organizações (CERNE, et al., 2014; IM; MONTOYA; WORKMAN JR, 2013). Em sendo um elemento de significante destaque, há que se gerenciá-lo e, consequentemente, mensurá-lo (SANTHOSHKUMAR; RAJASEKAR, 2012). Neste sentido, uma das primeiras e mais respeitadas formas de aferir a criatividade organizacional é o modelo KEYS, apresentado por Teresa Amabile, Robert Burnside e Stanley Gryskiewicz, conforme mostrado na Figura 3: 


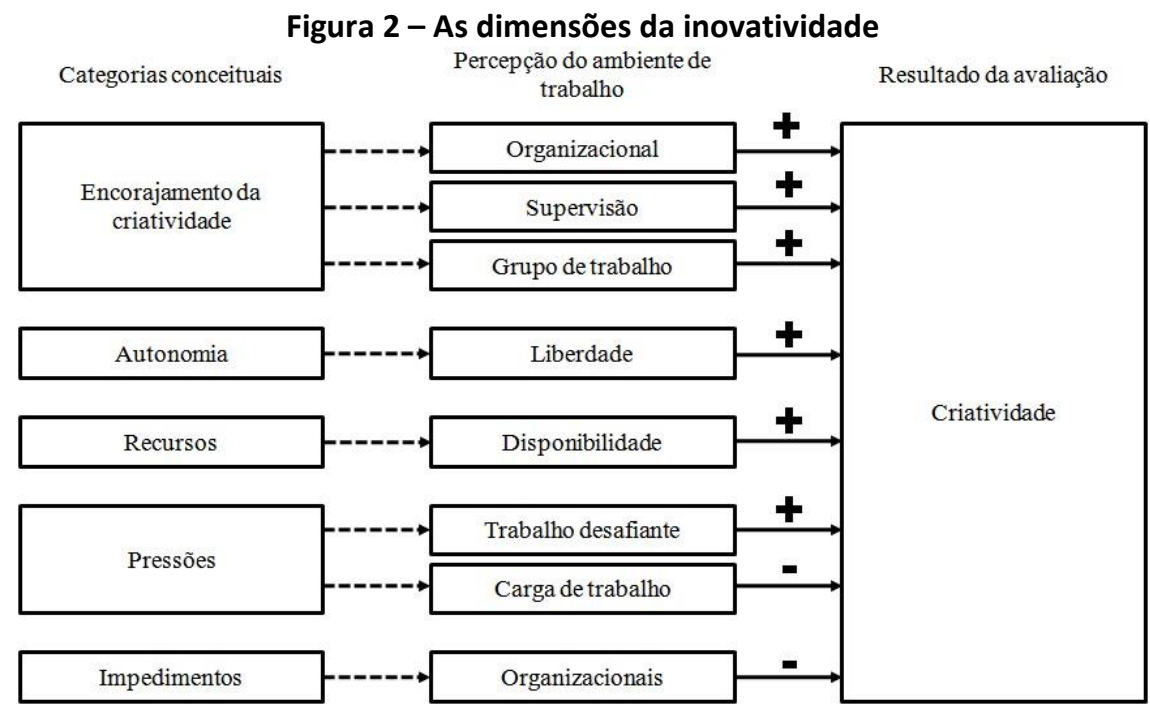

Fonte: adaptado de Amabile, et al (1996).

O modelo apresentado na Figura 3 avalia quantitativamente a contribuição do clima organizacional para a criatividade, a partir da percepção das pessoas no ambiente de trabalho (AXELSSON; SARDARI, 2011). É um instrumento de destaque, em comparação com outras ferramentas que buscam aferir a criatividade nas organizações, bem como permite aferir a efetividade dos efeitos organizacionais para um aperfeiçoamento contínuo (MATHISEN; EINARSEN, 2004). Além disto, apresenta convergência com os conceitos de criação do conhecimento (NONAKA; TAKEUCHI, 1997) e no ambiente onde as relações entre os indivíduos ocorrem (NONAKA; KONNO, 1998).

\section{PROCEDIMENTOS METODOLÓGICOS}

Trata-se de uma pesquisa que emprega análises estatísticas bi e multivariadas no intuito de tornar explícitas as características de condições habilitadoras da inovação, gestão do conhecimento e, criatividade organizacional, comuns às empresas que apresentam semelhantes desempenhos inovadores.

O instrumento de coleta de dados utilizado foi composto de cinco blocos: caracterização da empresa, Inovatividade (IN), Gestão do Conhecimento (GC), Criatividade Organizacional (CO) e Desempenho Inovador (DI). O primeiro deles trata da caracterização da empresa e é formado por questões abertas que abordam o ano de fundação da empresa, número de colaboradores, número de clientes em carteira e, principais produtos e serviços fornecidos pela empresa; bem como questão fechada, numérica ordinal, representando as classes de faturamento (AGÊNCIA NACIONAL DE VIGILÂNCIA DE SANITÁRIA, 2013, p. 1). A razão destas questões apoia-se na necessidade de se verificar a possibilidade da GC, IN, CO e DI estarem associadas a uma (ou mais) característica da empresa.

O segundo bloco de questões aborda as condições habilitadoras da inovação, denominadas como Inovatividade (IN), adaptado do modelo das 10 dimensões da inovatividade (QUANDT; BEZERRA; FERRARESI, 2015) mantendo-se, para cada dimensão, as duas variáveis com as maiores cargas fatoriais, mostradas no Quadro 1: 
Quadro 1 - Dimensões da inovatividade

Questões
Quanto à estratégia, na organização em que atuo...
... os componentes estratégicos (declaração de missão, visão, valores,
objetivos) priorizam a inovação.
... o desempenho estratégico é monitorado e avaliado, bem como o
processo de inovação.

Quanto à liderança, na organização em que atuo...

... os líderes promovem o compartilhamento e aprendizagem, demonstrando isso pelo próprio exemplo.

... os líderes buscam constantemente soluções novas e pouco usuais, estimulando novas ideias.

Quanto à cultura, na organização em que atuo...

... ocorre formação equipes multidisciplinares com autonomia para desenvolver projetos inovadores.

... há elevado sentimento de confiança entre empresa e funcionários.

Quanto à estrutura, na organização em que atuo...

... a estrutura facilita que pessoas de áreas distintas desenvolvam inovações.

... a estrutura organizacional facilita a mobilidade entre cargos e ampla comunicação entre departamentos.

Quanto aos processos, na organização em que atuo...

... é adotado um processo formal de gerenciamento de projetos para implantar inovações.

... existem métodos claros para planejamento de todo o ciclo de desenvolvimento de novos produtos.

Quanto às pessoas, na organização em que atuo...

... o processo de recrutamento e seleção valoriza o comportamento inovador e empreendedor.

... existem estratégias explícitas para a retenção de talentos para a inovação na empresa.

Quanto ao networking, na organização em que atuo...

... há vínculos parcerias com universidades e institutos de pesquisa com seus objetivos estratégicos.

... os funcionários sabem da importância das redes externas como forma de sustentação da competitividade.

Quanto às TICS, na organização em que atuo...

... as informações mais relevantes estão documentadas e organizadas em espaços virtuais de acesso geral.

... as pessoas usam efetivamente os recursos de acesso e compartilhamento dos sistemas de informações.

\section{Suporte teórico}

Cabral (2007); Oke,

Walumbwa e Myers (2012);

Prester e Bozac (2012)

Denti e Hemlin (2012);

Suriyamurthi, Velavan e Radhiha (2013); Vacaro, et al., (2012).

Brockman, Jones e

Becherer (2012); Rubera e Kirca (2012).

Prester e Bozac (2012);

Uzkurt, et al., (2012).

Rubera e Kirca (2012); Sheu e Lee (2011). (2012); Dotzel, Shankar e Berry (2013); Mieres, Sánchez e Vijande (2012).

Claub (2012); Dotzel, Shankar e Berry (2013); Lasagni (2012).

Abecassis-Moedas e Bengozi (2012); Brockman, Jones e Becherer (2012); Dotzel, Shankar e Berry (2013).

Autant-Bernard, et al., (2010); Rao (2010).

... existem mecanismos formais para se comparar com a concorrência.

... os resultados são medidos sob várias perspectivas e usa as medidas como forma de aprendizado.

Quanto à aprendizagem, na organização em que atuo...

... a avaliação do desempenho é uma atividade de aprendizagem, e não punitiva ou controladora.

Brockman, Jones e

Becherer (2012); Mieres, Sánchez e Vijande (2012). ... o aprendizado é uma responsabilidade integral e diária de todos.

Fonte: adaptado de Quandt, Bezerra e Ferraresi (2015)

Para as capacidades organizacionais de GC adaptou-se o modelo que avalia os aspectos capacitadores da gestão do conhecimento (GOLD; MALHOTRA; SEGARS, 2001), agrupando-se por similaridade, algumas questões e eliminando-se aquelas que tratam

Perspectivas em Gestão \& Conhecimento, João Pessoa, v. 7, n. 1, p. 70-97, jan./jun. 2017. 
especificamente da proteção do conhecimento, por não estarem alinhadas à proposta da presente pesquisa. O Quadro 2 mostra as questões empregadas:

Quadro 2 - Gestão do conhecimento

\begin{tabular}{|c|c|}
\hline Questões & Suporte teórico \\
\hline $\begin{array}{l}\text { Quanto à cultura organizacional, na organização em que atuo... } \\
\text {... a visão geral está claramente comunicada. } \\
\text {... as pessoas são encorajadas a explorar e a experimentar. } \\
\text {... as pessoas são encorajadas a pedir ajuda quando necessário. }\end{array}$ & $\begin{array}{l}\text { Christopher e Tanwar (2012); } \\
\text { Pugna e Boldeanu (2014); } \\
\text { Taylor (2013). }\end{array}$ \\
\hline $\begin{array}{l}\text { Quanto à estrutura organizacional, na organização em que atuo... } \\
\text {... a divisão departamental estimula a interação e o } \\
\text { compartilhamento de conhecimento. } \\
\text {... existe um sistema formal de recompensa ao compartilhamento } \\
\text { do conhecimento. } \\
\text {... existem estruturas nas quais o comportamento coletivo é } \\
\text { predominante ao comportamento individual. }\end{array}$ & $\begin{array}{l}\text { Saini (2013); Prado e Fischer } \\
\text { (2013); von Krogh, Nonaka e } \\
\text { Rechsteiner (2012). }\end{array}$ \\
\hline $\begin{array}{l}\text { Quanto à tecnologia empregada na organização em que atuo... } \\
\text {... possibilita a colaboração entre pessoas. } \\
\text {... formata e categoriza o conhecimento para usos futuros. } \\
\text {... possibilita o acesso ao conhecimento quando necessário. }\end{array}$ & $\begin{array}{l}\text { Chadha e Saini (2014); Naila, et } \\
\text { al., (2014); Nandita (2013). }\end{array}$ \\
\hline $\begin{array}{l}\text { Quanto à aquisição do conhecimento, na organização em que atuo... } \\
\text {... esta é uma prática formal. } \\
\text {... existem processos para compartilhamento de conhecimento } \\
\text { com parceiros. } \\
\text {... existem processos formais para identificação de melhores } \\
\text { práticas. }\end{array}$ & $\begin{array}{l}\text { Dong, Johar e Kumar (2012); } \\
\text { Hawkins, Nissen e Rendon } \\
\text { (2014); Mageswari, } \\
\text { Sivasubramanian, e Dath } \\
\text { (2015). }\end{array}$ \\
\hline $\begin{array}{l}\text { Quanto à conversão do conhecimento, na organização em que atuo... } \\
\text {... existem processos para descartar, repor e filtrar o } \\
\text { conhecimento. } \\
\text {... existem processos formais para compartilhamento entre os } \\
\text { colaboradores. } \\
\text {... existem processos formais para conversão do conhecimento em } \\
\text { novos produtos/serviços. }\end{array}$ & $\begin{array}{l}\text { Hayes e Walsham (2005); } \\
\text { McFadden, et al., (2014); } \\
\text { Takeuchi e Nonaka (2008). }\end{array}$ \\
\hline $\begin{array}{l}\text { Quanto à aplicação do conhecimento, na organização em que atuo... } \\
\text {... existem processos para aplicar o conhecimento criado a partir } \\
\text { de experiências. } \\
\text {... existem fontes formais de conhecimento para abordar novos } \\
\text { desafios. } \\
\text {... o conhecimento é rapidamente aplicada na solução de } \\
\text { problemas. }\end{array}$ & $\begin{array}{l}\text { Bezerra, Barbosa e Espejo } \\
\text { (2013); Jeng e Dunk (2013); } \\
\text { Mclver, et al., (2013). }\end{array}$ \\
\hline
\end{tabular}

Fonte: adaptado de Gold, Malhotra e Segars (2001)

Em relação às condições ambientais para a Criatividade Organizacional (CO) adotou-se a abreviação do modelo KEYS (AMABILE, et al., 1996) proposta por Rosello e Tran (2011), mostrado no Quadro 3:

Quadro 3-Criatividade organizacional

\begin{tabular}{|l|l|}
\hline Questões & Suporte teórico \\
\hline $\begin{array}{l}\text { Quanto ao encorajamento organizacional, na organização em } \\
\text { que atuo... } \\
\quad . . \text { novas ideias são regularmente encorajadas. } \\
\quad . . \text { as pessoas são reconhecidas pela criatividade. } \\
\ldots \text { as pessoas são recompensadas pela criatividade. }\end{array}$ & $\begin{array}{l}\text { Adeney (2012); De Stobbeleir, } \\
\text { Ashford e Buyens (2011); Zhang e } \\
\text { Bartol (2010). }\end{array}$ \\
\hline
\end{tabular}

Perspectivas em Gestão \& Conhecimento, João Pessoa, v. 7, n. 1, p. 70-97, jan./jun. 2017. 


\begin{tabular}{|c|c|}
\hline $\begin{array}{l}\text { Quanto ao encorajamento da supervisão, na organização em que } \\
\text { atuo... } \\
\quad \ldots \text { os supervisores comunicam claramente os objetivos à } \\
\text { equipe. } \\
\text {... os supervisores possuem boas habilidades interpessoais. } \\
\text {... os supervisores apoiam as equipes de trabalho. }\end{array}$ & $\begin{array}{l}\text { Chedli (2014); De Stobbeleir, } \\
\text { Ashford e Buyens (2011); Kim, Hon } \\
\text { e Lee (2010). }\end{array}$ \\
\hline $\begin{array}{l}\text { Quanto aos grupos de trabalho, na organização em que atuo... } \\
\text {... as pessoas se ajudam mutuamente. } \\
\text {... há um sentimento de confiança mútuo. }\end{array}$ & $\begin{array}{l}\text { Gonçalo, et al., (2015); Harvey } \\
\text { (2014); Jia, et al., (2014). }\end{array}$ \\
\hline $\begin{array}{l}\text { Quanto à disponibilidade de recursos, na organização em que } \\
\text { atuo... } \\
\quad \text {... os orçamentos são adequados. } \\
\text {... as pessoas conseguem os materiais necessários às suas } \\
\text { atividades com facilidade. }\end{array}$ & $\begin{array}{l}\text { Bakker e Xanthopoulou (2013); } \\
\text { Jaskyte, et al., (2010); Wang (2014). }\end{array}$ \\
\hline $\begin{array}{l}\text { Quanto aos desafios, na organização em que atuo... } \\
\text {... as tarefas desafiam as capacidades dos colaboradores. } \\
\text {... as pessoas se sentem desafiadas. }\end{array}$ & $\begin{array}{l}\text { Gong, et al., (2013); Hirst, et al., } \\
\text { (2011); Tsaur, Yen e Yang (2011). }\end{array}$ \\
\hline $\begin{array}{l}\text { Quanto à liberdade de ação, na organização em que atuo... } \\
\text {... as pessoas têm liberdade de decidir como conduzir seus } \\
\text { projetos. } \\
\text {... as pessoas têm liberdade de escolher em qual projeto irão } \\
\text { participar. }\end{array}$ & $\begin{array}{l}\text { Sagiv, et al., (2010); Romeiro e } \\
\text { Wood Jr (2015); Wang e Cheng } \\
\text { (2010). }\end{array}$ \\
\hline $\begin{array}{l}\text { Quanto aos impedimentos organizacionais, na organização em } \\
\text { que atuo... } \\
\quad \text {... existem problemas políticos. } \\
\text {... as pessoas são resistentes às novas ideias. } \\
\text {... existem competições que podem ser destrutivas. } \\
\text {... a alta gerência não assume riscos. }\end{array}$ & $\begin{array}{l}\text { Chua (2013); Hirst, et al., (2011); } \\
\text { Romeiro e Wood Jr (2015). }\end{array}$ \\
\hline $\begin{array}{l}\text { Quanto à carga de trabalho, na organização em que atuo... } \\
\text {... existe uma forte pressão em relação aos prazos. } \\
\text {... as expectativas são realistas em relação aos objetivos } \\
\text { traçados. }\end{array}$ & $\begin{array}{l}\text { Cäniels e Rietzschel (2013); Pan, Sun } \\
\text { e Chow (2012); Romeiro e Wood Jr } \\
\text { (2015). }\end{array}$ \\
\hline
\end{tabular}

Fonte: adaptado de Rosello e Tran (2011)

Para obter as opiniões quanto ao Desempenho Inovador (DI) utilizou-se das sete questões empregadas no modelo das 10 dimensões da inovatividade (QUANDT; BEZERRA; FERRARESI, 2015), conforme mostrado no Quadro 4:

Quadro 4-Desempenho inovador

\begin{tabular}{|c|c|}
\hline Questões & Suporte teórico \\
\hline $\begin{array}{l}\text { Quanto aos produtos/serviços desenvolvidos, na organização em que } \\
\text { atuo... } \\
\text {... são frequentemente percebidos, pelos clientes, como muito } \\
\text { criativos. } \\
\text {... temos lançados produtos/serviços mais criativos em relação aos } \\
\text { concorrentes. } \\
\text {... temos lançados produtos/serviços mais rapidamente em relação } \\
\text { aos concorrentes. } \\
\text {... a participação de novos produtos/serviços na receita total tem sido } \\
\text { maior em relação aos concorrentes. }\end{array}$ & $\begin{array}{l}\text { Autant-Bernard, et al., } \\
\text { (2010); Oke, Walumbwa e } \\
\text { Myers (2012); Rubera e } \\
\text { Kirca (2012). }\end{array}$ \\
\hline $\begin{array}{l}\text { Quanto aos processos internos, na organização em que atuo... } \\
\text {... implementamos um alto percentual de melhorias. } \\
\text {... conquistamos melhorias significativas no processo de produção. } \\
\text {... conquistamos melhorias significativas nos processos }\end{array}$ & $\begin{array}{l}\text { Cepeda-Carrion, Cegarra- } \\
\text { Navarro e Jimenez-Jimenez } \\
\text { (2012); Dabla-Norris, et al., } \\
\text { (2012); Remneland- }\end{array}$ \\
\hline
\end{tabular}

Perspectivas em Gestão \& Conhecimento, João Pessoa, v. 7, n. 1, p. 70-97, jan./jun. 2017. 
organizacionais.

Fonte: adaptado de Quandt, Bezerra e Ferraresi (2015)
Wikhamn e Wikhamn

(2011).

Optou-se por adaptar os instrumentos de coleta de dados originais (ou empregar modelos adaptados), em virtude do (1) elevado número de questões decorrentes e, (2) ocorrência de questões repetidas entre os questionários. Cada assertiva das referidas seções corresponde a uma questão numérica intervalar em uma escala de 0 a 10, que representa a intensidade com que aquelas práticas organizacionais, bem como o desempenho inovador, ocorrem nas empresas (a opção 0 indica a não existência da prática).

O levantamento de dados, por conveniência geográfica, foi efetuado em uma população de 252 agências vinculadas ao SINAPRO/PR e CENP, que se mantinham em atividade no Paraná, quando da aplicação do questionário aos proprietários das agências entre 11 de outubro de 2013 e 11 de dezembro de 2013. Da população originalmente estabelecida, obteve-se 60 respostas válidas (todas circunscritas ao município de Curitiba) o que não foi suficiente para representar a população, com um intervalo de confiança de $95 \%$ e erro amostral de $5 \%$, sendo que, portanto, as conclusões não são passíveis de generalizações, referindo-se, exclusivamente, à amostra coletada. Em que pese o fato da escolha da população ter sido conduzida por conveniência, o estado do Paraná tem demonstrado posição de destaque no contexto nacional dos investimentos em publicidade. Segundo Favretto (2012, p.1), citando Kal Gelbecke, em 2011 "os gastos com publicidade [...] somaram aproximadamente R\$ 2,4 bilhões", associado ao fato da "entrada das classes C e D no mercado consumidor e, também, pela expansão das cidades do interior" ter impulsionado ainda mais o aumento de investimentos, cuja previsão de crescimento para 2012 foi de $8 \%$. Já no primeiro semestre de 2014, entre as capitais, a cidade de Curitiba foi a quinta colocada nas que mais registraram investimentos publicitários (IBOPE, 2014).

Visto que, pelo teste de Kolmogorov-Smirnov, apenas 10,6\% das variáveis não apresentaram desvios em suas distribuições em relação à curva normal, optou-se por submeter todas as variáveis à análise de correspondência múltipla, uma vez que se trata de técnica que não faz suposições sobre a distribuição dos dados, bem como a testes auxiliares não paramétricos. Além disto, esta escolha ampara-se também na natureza qualitativa destas variáveis - que expressam a percepção dos respondentes quanto à $\mathrm{GC}, \mathrm{CO}, \mathrm{IN}$ e DI. A análise seguiu os procedimentos descritos no protocolo apresentado no Quadro 5:

Quadro 5 - Protocolo de análise

\begin{tabular}{|c|c|c|c|}
\hline Etapas & Objetivos & Procedimentos & Suporte teórico \\
\hline 1 & $\begin{array}{l}\text { Prover uma visão geral das } \\
\text { características das empresas } \\
\text { respondentes. }\end{array}$ & $\begin{array}{l}\text { Estatística descritiva (médias, } \\
\text { desvios padrão, frequências). }\end{array}$ & $\begin{array}{l}\text { Cooper e Schindler } \\
\text { (2003), Hair Jr, et al } \\
\text { (2005) }\end{array}$ \\
\hline 2 & $\begin{array}{l}\text { Avaliar a confiabilidade interna dos } \\
\text { conjuntos de questões submetidas aos } \\
\text { respondentes. }\end{array}$ & Alfa de Cronbach. & $\begin{array}{l}\text { Maroco e Garcia- } \\
\text { Marques (2006) }\end{array}$ \\
\hline 3 & $\begin{array}{l}\text { Agrupar os resultados das variáveis de } \\
\text { GC, CO, IN e DI }\end{array}$ & Percentil. & Fávero, et al (2009) \\
\hline 4 & Recategorizar as variáveis agrupadas. & $\begin{array}{l}\text { Abaixo de } 33 \% \text { = Baixo; } \\
\text { Entre } 33,01 \% \text { e } 66 \% \text { = Médio; } \\
\text { Acima de } 66 \% \text { = Alto. }\end{array}$ & \\
\hline 5 & $\begin{array}{l}\text { Avaliara a existência de relações entre } \\
\text { as variáveis de caracterização da } \\
\text { empresa e características de GC, CO, } \\
\text { IN e DI. }\end{array}$ & $\begin{array}{l}\text { H de Kruskal-Wallis, chi- } \\
\text { quadrado. }\end{array}$ & Field (2009) \\
\hline
\end{tabular}

Perspectivas em Gestão \& Conhecimento, João Pessoa, v. 7, n. 1, p. 70-97, jan./jun. 2017. 


\begin{tabular}{|c|c|c|c|c|}
\hline 6 & $\begin{array}{l}\text { Verificar a independência das } \\
\text { variáveis. }\end{array}$ & \multicolumn{2}{|c|}{ Chi-quadrado. } & Lombardo e Beh (2010) \\
\hline 7 & $\begin{array}{l}\text { Determinar o número de dimensões a } \\
\text { serem analisadas. }\end{array}$ & \multirow{5}{*}{ 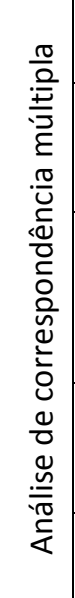 } & Autovalores e inércia. & Carvalho (2008) \\
\hline 8 & $\begin{array}{l}\text { Avaliar a confiabilidade do conjunto de } \\
\text { variáveis escolhidas para serem } \\
\text { representadas nas dimensões. }\end{array}$ & & $\begin{array}{l}\text { Alfa de Cronbach médio } \\
\text { dos autovalores médios. }\end{array}$ & $\begin{array}{l}\text { Maroco e Garcia- } \\
\text { Marques (2006), } \\
\text { Carvalho (2008) }\end{array}$ \\
\hline 9 & $\begin{array}{l}\text { Avaliar a variância explicada para as } \\
\text { dimensões. }\end{array}$ & & $\begin{array}{l}\text { Percentual da inércia de } \\
\text { cada dimensão em } \\
\text { relação ao total das } \\
\text { inércias. }\end{array}$ & Fávero, et al (2009) \\
\hline 10 & Determinar as coordenadas dos eixos. & & $\begin{array}{l}\text { Frequências, massas e } \\
\text { autovalores das } \\
\text { categorias; escores. }\end{array}$ & Fávero, et al (2009) \\
\hline 11 & $\begin{array}{l}\text { Visualizar a distribuição do conjunto } \\
\text { de pontos das categorias. }\end{array}$ & & $\begin{array}{l}\text { Gráfico da quantificação } \\
\text { das categorias. }\end{array}$ & $\begin{array}{l}\text { Fávero, et al (2009), } \\
\text { Carvalho (2008) }\end{array}$ \\
\hline 12 & $\begin{array}{l}\text { Avaliar a intensidade de associação } \\
\text { das categorias. }\end{array}$ & \multicolumn{2}{|c|}{$\begin{array}{l}\text { Coeficiente de correlação de } \\
\text { Pearson. }\end{array}$} & Field (2009) \\
\hline
\end{tabular}

Fonte: os autores (2015)

Para as análises, empregaram-se os softwares PASW Statistics $18{ }^{\circledR}$ e Microsoft Office Excel $2007{ }^{\circledR}$, sendo que, nos testes empregados, considerou-se um nível de significância esperado de 0,05 .

\section{ANÁLISE E DISCUSSÃO DE RESULTADOS}

O corpo de respondentes pode ser assim descrito:

- Quanto ao ano de fundação: em média, as organizações possuem 12,3 anos de existência, com desvio padrão de 9,5, sendo que a mais antiga foi fundada em 1966 e a mais atual, em 2011.

- Quanto ao número de colaboradores: as empresas respondentes possuem, em média, 21,93 colaboradores, com desvio padrão de 31,39. O menor número de colaboradores, três, foi encontrado em duas agências e, o maior, 170, em uma única empresa.

- Em relação às classes de faturamento, $81,67 \%$ se classificaram como possuindo faturamento inferior a $R \$ 3.600 .000,00$ anuais; $11,67 \%$ acima ou igual a este valor e abaixo de $\mathrm{R} \$ 20.000 .000,00$ e; $5 \%$ informaram ter faturado acima ou igual a $\mathrm{R} \$ \mathbf{2 0 . 0 0 0 . 0 0 0 , 0 0}$ em 2013 - uma empresa não respondeu a esta questão.

- Para a principal atividade desempenhada pelas empresas, $13,33 \%$ indicaram ser "Branding"; 13,33\%, "Comunicação"; 23,33\%, "Design gráfico"; 6,67\% informaram que sua principal atividade é "Mídia"; 8,33\%, "Planejamento estratégico"; 6,67\%, "Planejamento de marketing"; 20\%, "Publicidade e propaganda" e; $8,33 \%$ declararam outras atividades.

Quanto às questões que envolvem $\mathrm{GC}, \mathrm{CO}, \mathrm{IN}$ e $\mathrm{DI}$, dado o elevado número de itens, estes não serão analisados individualmente, mas sim pelos seus agrupamentos. Neste caso, primeiramente há que se verificar, pelo teste alfa de Cronbach, a confiabilidade dos construtos formados. Assim sendo, registram-se os valores de 0,949 para o grupo de GC; 0,829 para a CO; 0,916 para IN e; 0,895 para DI. Estes resultados indicam elevada confiabilidade para as

Perspectivas em Gestão \& Conhecimento, João Pessoa, v. 7, n. 1, p. 70-97, jan./jun. 2017. 
variáveis que formam os conjuntos de GC, CO, IN e DI. Assim sendo, estas variáveis foram agrupadas pelos respectivos percentis, em cada conjunto, e classificadas em: "baixo", quando o percentil atingiu um valor igual ou inferior a $33 \%$; "alto", acima de $66 \%$ e; "médio" acima de $33 \%$ e igual ou inferior a $66 \%$. Este procedimento resultou na seguinte distribuição de frequências:

Quadro 6 - Frequência de percepções de GC, CO
\begin{tabular}{|l|c|c|c|c|}
\hline Percepção & GC & CO & IN & DI \\
\hline Baixo & 2 & 0 & 2 & 4 \\
\hline Médio & 21 & 10 & 30 & 23 \\
\hline Alto & 37 & 50 & 28 & 33 \\
\hline
\end{tabular}

Fonte: Dados da pesquisa, 2015.

Cruzando-se os dados de caracterização de empresas e percepção de GC, CO, IN e DI, obtêm-se o seguinte panorama:

- Quanto ao tempo de existência, não é possível afirmar que esta variável apresenta diferenças estatisticamente significantes nos grupos de $\mathrm{GC}(\mathrm{H}(2)=$ 0,719, p-valor <0,698), $\mathrm{CO}(\mathrm{H}(2)=1,963, \mathrm{p}$-valor $<0,161)$, IN $(\mathrm{H}(2)=3,764, \mathrm{p}$ valor $<0,152)$ e, DI $(H(2)=1,693, p$-valor $<0,429)$.

- Da mesma forma, as diferenças para o número de colaboradores não foram consideradas significativas para os seguintes grupos: $\mathrm{GC}(\mathrm{H}(2)=2,220$, $\mathrm{p}$-valor $<0,330), \mathrm{CO}(\mathrm{H}(2)=1,563$, p-valor $<0,207)$ e, $\mathrm{DI}(\mathrm{H}(2)=4,341$, p-valor $<0,114)$. Para a IN, o teste $\mathrm{H}$ de Kruskal-Wallis acusou diferenças neste grupo $(H(2)=$ 6,026 , p-valor $<0,049$ ). Estas residem no fato de que empresas que percebem baixas condições organizacionais para a inovatividade apresentaram, em média, 5,5 colaboradores (com desvio padrão de 0,5 ); enquanto que naquelas em que a percepção foi considerada média, o número de colaboradores é de 14,97 (com desvio padrão de 2,36) e; nas de maior percepção, a média de colaboradores atingiu 30,57 (com desvio padrão de 8,06).

- Quando comparados com os grupos de faturamento, é possível afirmar que não existem distinções estatisticamente significantes entre os grupos de GC $(X 2(4)=0,642$, $p$-valor <0,958), CO (X2(4) = 2,4, p-valor <0,301), IN (X2(4) = 1,176, $p$-valor $<0,882)$ e, DI (X2(4) = 5,467, $p$-valor $<0,243)$.

- Similar aos achados em relação ao faturamento, as atividades das empresas não as diferenciam significativamente quanto à $\mathrm{GC}(\mathrm{X2} 2(14)=11,164, \mathrm{p}$-valor $<$ 0,673), CO (X2(14) = 5,597, p-valor < 0,587), IN (X2(14) = 11,315, p-valor < $0,661)$ e, DI (X2(14) = 9,440, p-valor $<0,802)$.

Desta maneira, assume-se que as diferenças encontradas não foram sistemáticas. Isto indica que a GC, CO, IN e DI, na amostra obtida, independem das características das empresas - com exceção do fato de uma das condições habilitadoras da inovação ser percebida mais intensamente em empresas com maior número de colaboradores.

A próxima etapa busca por diferenças de percepções em relação aos grupos de GC, CO, IN e DI, conforme os resultados do teste do chi-quadrado apresentados no Quadro 7: 
Quadro 7 - Diferenças entre grupos

\begin{tabular}{|c|l|c|c|c|}
\hline Grupo & Estatística & GC & CO & IN \\
\hline \multirow{2}{*}{ CO } & $X^{2}(4)$ & 19,395 & & \\
\cline { 2 - 5 } & p-valor & 0,000 & & \\
\hline \multirow{2}{*}{ IN } & $X^{2}(4)$ & 29,851 & 14,417 & \\
\cline { 2 - 5 } & p-valor & 0,000 & 0,001 & \\
\hline \multirow{2}{*}{ DI } & $X^{2}(4)$ & 17,712 & 10,757 & 52,084 \\
\cline { 2 - 5 } & p-valor & 0,001 & 0,005 & 0,000 \\
\hline
\end{tabular}

Fonte: Dados da pesquisa, 2015.

É possível afirmar que existe independência das percepções os grupos de GC, CO, IN e DI, quando comparados entre si. No sentido de tornar estas diferenças visivelmente explícitas empregou-se a análise de correspondência múltipla. Como o objetivo desta análise é distribuir as variáveis em um espaço de $\mathrm{n}$ dimensões, primeiramente há que se estabelecer o número mais adequado de dimensões (ou eixos) à representatividade dos grupos. Para os dados obtidos na amostra, determinou-se o número máximo de dimensões obtido a partir da diferença entre os números de categorias ativas e variáveis com as devidas respostas, chegouse a sete dimensões. No intuito de reduzir este número, há que se avaliar a capacidade de cada uma em representar os agrupamentos distribuídos. Uma das maneiras de se estabelecer o número mínimo aceitável é avaliando os autovalores e inércias de cada dimensão. O Quadro 8 mostra estes valores:

Quadro 8 - Autovalores e inércias do total de dimensões

\begin{tabular}{|l|c|c|c|c|c|c|c|}
\hline Dimensões & 1 & 2 & 3 & 4 & 5 & 6 & 7 \\
\hline Autovalores & 2,637 & 1,823 & 0,835 & 0,678 & 0,449 & 0,342 & 0,237 \\
\hline Inércias & 0,659 & 0,456 & 0,209 & 0,17 & 0,112 & 0,085 & 0,059 \\
\hline
\end{tabular}

Fonte: Dados da pesquisa, 2015.

Percebe-se que as duas primeiras dimensões são nitidamente mais representativas em termos de inércia, visto que explicam mais da metade $(63,71 \%)$ da inércia total de todas as dimensões. Assim sendo, obtendo-se o alfa de Cronbach médio para os autovalores médios de duas dimensões, nota-se que a primeira dimensão apresenta confiabilidade de moderada a elevada e a segunda, aceitável, conforme apresentado no Quadro 9:

Quadro 9 - Alfa de Cronbach, autovalores e inércias das dimensões analisadas

\begin{tabular}{|c|c|c|c|c|}
\hline Dimensões & Alfa de Cronbach & Autovalores & Inércias & $\%$ da variância \\
\hline 1 & 0,828 & 2,637 & 0,659 & $65,92 \%$ \\
\hline 2 & 0,602 & 1,823 & 0,456 & $45,57 \%$ \\
\hline
\end{tabular}

Fonte: Dados da pesquisa, 2015.

Além disto, as proporções percentuais das inércias de cada dimensão indicam que a primeira explica $59,1 \%$ e a segunda dimensão, $40,9 \%$ da inércia total, confirmando a representatividade da primeira dimensão (em relação à segunda) para o comportamento dos dados. Assim sendo, estabelece-se um número de dois eixos para a representação dos casos associados às variáveis a serem distribuídas no plano. dimensão:

Em relação às variáveis, o Quadro 10 mostra as que mais discriminam em cada 


Quadro 10 - Medidas de discriminação
\begin{tabular}{|c|c|c|c|}
\hline \multirow{2}{*}{ Variável } & \multicolumn{2}{|c|}{ Dimensão } & \multirow{2}{*}{ Média } \\
\cline { 2 - 4 } & 1 & 2 & \\
\hline GC & 0,664 & 0,408 & 0,536 \\
\hline CO & 0,555 & 0,000 & 0,278 \\
\hline IN & 0,760 & 0,757 & 0,759 \\
\hline DI & 0,658 & 0,657 & 0,658 \\
\hline
\end{tabular}

Fonte: Dados da pesquisa, 2015.

É possível notar que todas as variáveis são mais representativas na dimensão 1, porém não se pode ignorar o fato de que, especificamente, a IN e o DI na dimensão 2 apresentam valores muito próximos aos da dimensão 1 , indicando equilíbrio entre elas na capacidade de expressá-las. É notável que a CO não é representada, em absoluto, pela dimensão 2.

Para a determinação das coordenadas nos dois eixos (ou dimensões), levou-se em consideração a capacidade das categorias em representarem as similaridades e diferenças entre si, a partir da avaliação das frequências, massas e inércias, conforme mostrado no Quadro 11:

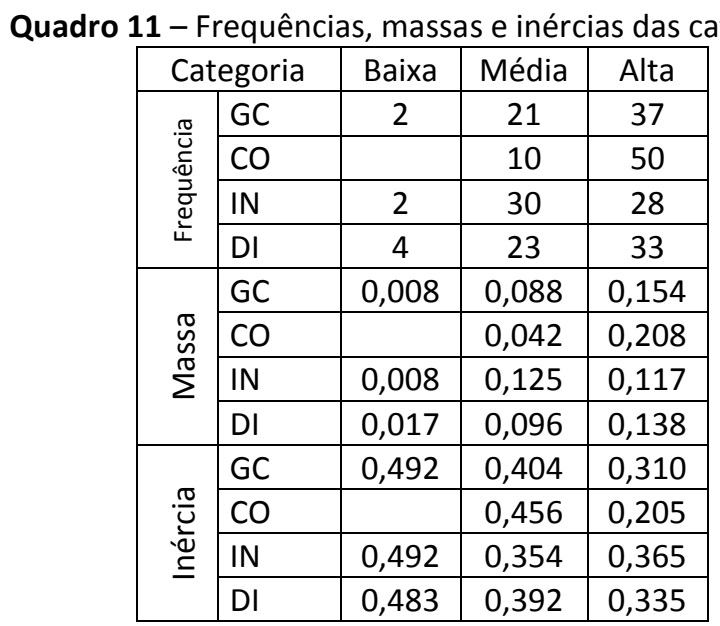

Fonte: Dados da pesquisa, 2015.

Os resultados mostram a concentração de casos que percebem a GC, CO, IN e DI com alta intensidade. As massas indicam que a $\mathrm{CO}$ é o elemento com maior influência sobre os demais, na categoria de alta percepção, enquanto que na categoria de média percepção, destaca-se a IN e, na de baixa, o DI. Já as inércias mostram que a variância total é mais bem explicada nos elementos de grupos de GC, $\mathrm{CO}$ e DI nos grupos de média intensidade e, IN no grupo de alta intensidade. Ainda assim, é importante ressaltar que, tanto os valores das massas, quanto os dos autovalores, não são elevados - é preciso cautela na interpretação destes resultados.

A partir dos valores obtidos no Quadro 11, empregando-se o método da normalização simétrica, é possível estabelecer as coordenadas (escores) de cada grupo em um plano de duas dimensões. O Quadro 12 mostra os escores quantificados para cada elemento em relação às percepções e, nestas, ambas as dimensões:

Quadro 12 - Escores das categorias

\begin{tabular}{|c|c|c|c|c|c|c|}
\hline \multirow{2}{*}{ Elementos } & \multicolumn{2}{|c|}{ Baixa } & \multicolumn{2}{c|}{ Média } & \multicolumn{2}{c|}{ Alta } \\
\cline { 2 - 7 } & 1 & 2 & 1 & 2 & 1 & 2 \\
\hline \multirow{2}{*}{ GC } & 3,064 & 2,292 & 0,682 & $-0,722$ & $-0,552$ & 0,286 \\
\hline
\end{tabular}

Perspectivas em Gestão \& Conhecimento, João Pessoa, v. 7, n. 1, p. 70-97, jan./jun. 2017. 


\begin{tabular}{|c|c|c|c|c|c|c|}
\hline CO & & & 1,666 & 0,017 & $-0,333$ & $-0,003$ \\
\hline IN & 3,511 & 3,379 & 0,447 & $-0,709$ & $-0,73$ & 0,518 \\
\hline DI & 2,208 & 1,978 & 0,532 & $-0,903$ & $-0,639$ & 0,39 \\
\hline
\end{tabular}

Fonte: Dados da pesquisa, 2015.

Assim sendo, as coordenadas quantificadas podem ser expressas em um gráfico bidimensional, apresentado na Figura 4:

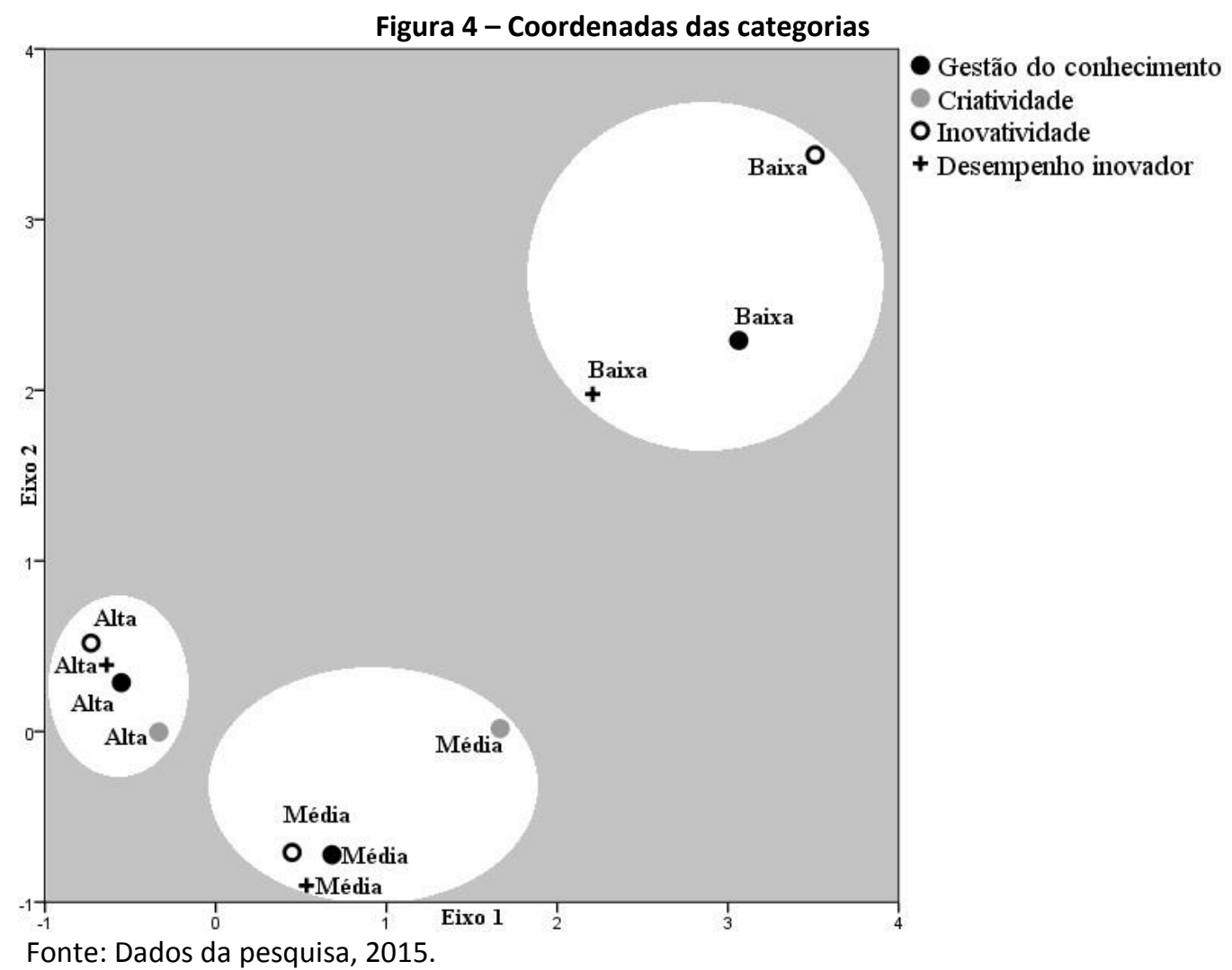

Observa-se a existência de agrupamentos distintos formados pela intensidade da percepção com que os elementos de GC, CO, IN e DI, de tal forma que, as empresas cujos respondentes notam mais intensamente estas práticas, também são aquelas que apresentam maior percepção no DI. O mesmo fato pode ser encontrado no agrupamento de respostas em que os mesmos quesitos são percebidos com média intensidade e, bem como, naqueles casos onde a percepção é baixa. Destaca-se que não foram registrados casos de baixa criatividade organizacional.

Além disto, o Quadro 13 apresenta os resultados para os coeficientes de correlação de Pearson, para as variáveis transformadas, indicando que a variação da intensidade de percepção da GC, sozinha, explica $32,26 \%$ da variação da CO e $35,40 \%$ da IN. Por sua vez, a variação da IN é responsável por mais da metade da variação do DI (51,55\%), comprovando as evidências apontadas em estudos anteriores (QUANDT; BEZERRA; FERRARESI, 2015): 
Quadro 13 - Correlações das variáveis transformadas

\begin{tabular}{|l|l|c|c|c|}
\hline \multirow{2}{*}{ Variável } & Estatística & GC & CO & IN \\
\hline \multirow{2}{*}{ CO } & $r$ & 0,568 & & \\
\cline { 2 - 5 } & $p$-valor & 0,000 & & \\
\hline \multirow{2}{*}{ IN } & $r$ & 0,595 & 0,483 & \\
\cline { 2 - 5 } & $p$-valor & 0,000 & 0,000 & \\
\hline \multirow{2}{*}{ DI } & $r$ & 0,483 & 0,414 & 0,718 \\
\cline { 2 - 5 } & $p$-valor & 0,000 & 0,001 & 0,000 \\
\hline
\end{tabular}

Fonte: Dados da pesquisa, 2015.

Não se descartam, também, as demais correlações, cujos valores indicam moderadas associações entre as variáveis.

De maneira geral, na amostra obtida, os resultados indicam que características como tempo de existência, faturamento e ramo de atividades desempenhadas pelas empresas de publicidade, não as diferenciam pela intensidade percebida por seus gestores quanto às práticas de GC, CO, IN e tampouco quanto ao próprio desempenho inovador. Por outro lado, ainda em relação às características das empresas, nota-se que empresas com maior número de funcionários apresentam condições organizacionais para a inovatividade mais intensamente percebidas, em relação às de menor porte.

Em relação à distribuição das categorias formadas pela percepção das condições habilitadoras da inovação (IN), capacidades organizacionais de gestão do conhecimento (GC), condições ambientais para a criatividade organizacional (CO) e, desempenho inovador (DI), a análise empregada mostrou que as mesmas podem ser adequadamente distribuídas em um plano de duas dimensões, sem perda significativa de suas representatividades - de tal forma que, percebe-se equilíbrio entre as dimensões para a disposição dos elementos de IN e DI, enquanto que os elementos de GC encontram-se mais representados em uma das dimensões destacando o fato de que a CO é notada, exclusivamente, em apenas uma das dimensões.

Quanto à capacidade do método em esclarecer a variância nos grupos, nota-se que a GC, CO e IN estão mais aptas a explicá-la nos grupos de média intensidade de percepção, enquanto que a IN apresenta melhor desempenho, neste quesito, no grupo de alta intensidade. $\mathrm{O}$ cenário formado por estas condições mostra significativa proximidade nos agrupamentos de empresas onde, na medida em que a intensidade de percepção das práticas de GC aumenta, também aumentam as intensidades observadas nas práticas de $\mathrm{CO}$, IN e DI. Especificamente, o DI apresenta maior relação com as condições organizacionais habilitadoras da inovação, do que com os elementos de GC e CO. Por sua vez, os elementos de $\mathrm{CO}$ e IN mostram, no mínimo, moderadas associações às práticas de GC.

Julga-se necessário discutir os resultados encontrados à luz de pesquisas associadas à mesma temática. As correlações mostradas no Quadro 9 associam-se a muitos dos achados em estudos anteriores. Para Fibuch e van Way III (2011) sistemas robustos de GC podem ser vistos como sustentadores da inovação organizacional. Além disto, é recorrente a relação entre GC, inovação e criatividade. Segundo Charterina e Landeta (2013), a inovação decorre do conhecimento e está relacionada ao uso eficiente de ideias criativas. Da mesma forma, Camelo-Ordaz, et al., (2011) afirmam que o conhecimento intensivo, devidamente gerenciado, residente em equipes de pesquisa e desenvolvimento, constitui a principal fonte de criatividade e inovação das empresas. Para Christopher e Tanwar (2012) o conhecimento, adequadamente disponibilizado às pessoas, encoraja a criatividade e inovação entre o staff organizacional. Porém, há que se levar em consideração o fato de que existem conclusões contrárias às encontradas. Segundo Alvesson (2011), o trabalho de sistematização do conhecimento não é o principal elemento condutor da criatividade. Já Ibrahim e Reid (2010) argumentam que a GC foca demasiadamente em reciclar o conhecimento existente (como

Perspectivas em Gestão \& Conhecimento, João Pessoa, v. 7, n. 1, p. 70-97, jan./jun. 2017. 
difundir melhores práticas) do que gerar e criar novos conhecimentos, através da inovação. Ademais, parecem existir opiniões distintas quanto aos elementos antecedentes e consequentes. Enquanto que, nas conclusões anteriormente descritas, a GC é base para a inovação (e em algumas delas, também para a criatividade), autores como Sholla e Nazari (2011) colocam o conhecimento gerenciado como resultante de elementos como a inovação. Por sua vez, o Comitê Técnico de Gestão do Conhecimento e da Informação Estratégica, do Ministério do Planejamento, Orçamento e Gestão do Brasil, destaca que o conhecimento útil é decorrente da inovação e criatividade (FONSECA e FRESNEDA). Neste sentido, se os métodos empregados no presente estudo não permitem o estabelecimento de relações de causa e efeito, certamente comprovam a indissociabilidade entre a GC e inovação em empresas cujo principal serviço é decorrente de criatividade.

\section{CONSIDERAÇÕES FINAIS}

De maneira geral, quanto ao objetivo do estudo ('identificar a percepção com que as condições habilitadoras da inovação, os aspectos capacitadores da gestão do conhecimento e, as condições ambientais para a criatividade organizacional, encontram-se associadas ao desempenho inovador das empresas de publicidade'), na amostra coletada, o mesmo foi atingido, onde é possível afirmar que, na medida em que as empresas percebem mais intensamente os elementos de gestão do conhecimento (GC), criatividade organizacional (CO) e condições habilitadoras da inovação (IN), também mais intensa é a percepção do desempenho inovador (DI). Além disto, os resultados encontrados são indicativos de que os modelos distintos empregados para a avaliação destes elementos apresentam convergência entre si.

Entretanto, o estudo não está isento de limitações e, portanto, consequentes sugestões para pesquisas futuras. É possível argumentar que a validade do agrupamento dos dados por GC, CO, IN e DI, aferida pelo alfa de Cronbach, pode ter sido superestimada pelo número elevado de itens formadores dos grupos (CERVANTES, 2005). Por outro lado, as variáveis individuais apresentaram distribuições assimétricas - o que geralmente é associado a valores menores para o alfa (MAROCO e GARCIA-MARQUES, 2006). Estas mesmas situações (número de respostas e distribuição das variáveis) levou ao emprego de um método de análise que apesar de tornar explícita a associação e a correlação entre os elementos de GC, CO, IN e DI, não aponta para relações de causa e efeito. Assim sendo, é premente considerar, em futuras pesquisas que possam vir a empregar o mesmo instrumento de coleta de dados, a necessidade de um número mais elevado de respostas permitindo, desta forma, a utilização de métodos analíticos que possam indicar a existência de possíveis causas e efeitos. Deve ser registrado o fato de que, ao adaptar os instrumentos de coleta de dados originalmente propostos, ou utilizar aqueles já previamente adaptados, (ainda que se tenha preocupado com a manutenção da semântica de cada instrumento), não se descarta a possibilidade de perda de informações. Além disto, apesar da aferição de condições organizacionais empregando-se medidas que espelham a percepção dos respondentes ser recorrentemente utilizada (DOTZEL; SHANKAR; BERRY, 2013; UZKURT, et al., 2012; AKGÜN; KESKIN; BYRNE, 2012; CEPEDACARRION; CEGARRA-NAVARRO; JIMENEZ-JIMENEZ, 2012), se, por um lado, apresenta facilidade na obtenção dos dados, por outro, encontra sujeita aos vieses de natureza pessoais dos respondentes. Neste sentido, sugere-se que em pesquisas posteriores seja buscada a opinião, não somente do proprietário da empresa, mas também de seus funcionários, no intuito de que as respostas, no conjunto, forneçam uma visão mais consolidada do status da organização nos quesitos avaliados. Seja como for, a utilização de medidas obtidas a partir da percepção dos respondentes abre precedente para a discussão sobre a precisão destes elementos em relação à eficiência na coleta. Finalmente, ainda em relação às sugestões para

Perspectivas em Gestão \& Conhecimento, João Pessoa, v. 7, n. 1, p. 70-97, jan./jun. 2017. 
pesquisas futuras, recomenda-se a aplicação em empresas de segmentos diferentes, com o intuito de comparar o desempenho inovador a partir das práticas organizacionais.

De qualquer maneira, os resultados encontrados apresentam implicações tanto acadêmicas, quanto gerenciais. Para a academia, torna-se explícito, na amostra obtida, a associação entre os elementos de GC, $\mathrm{CO}$, IN e DI, cabendo, portanto, o aprofundamento de estudos que possam estabelecer a maneira como estas relações ocorrem em níveis operacionais, envolvendo tanto procedimentos organizacionais, como atores e responsabilidades. Para as empresas, a pesquisa fornece relações e subsídios para reflexão acerca dos benefícios da gestão do conhecimento, do cultivo da criatividade na organização e do foco estratégico nas condições orientadoras da inovação. Seja como for, o estudo contribui para um olhar interno às agências de publicidade, ainda que em elementos macro, estabelecendo um ponto inicial para pesquisas subsequentes, de modo que seja possível constituir um corpo de conhecimento sobre os componentes que garantam a competitividade neste segmento.

\section{REFERÊNCIAS}

ABECASSIS-MOEDAS, C.; BENGHOZI, P. J. Efficiency and innovativeness as determinants of design architecture choices. Journal of Product Innovation Management, v. 404, n. 417, p. 405-418, 2012.

ADENEY, E. The sampling and remix dilemma: what is the role of moral rights in the encouragement and regulation of derivative creativity? Deakin Law Review, v. 17, n. 2, p. 335348, 2012.

AGÊNCIA NACIONAL DE VIGILÂNCIA DE SANITÁRIA. Enquadramento de Porte da Empresa. ANVISA, $2013 . \quad$ Disponível em: http://portal.anvisa.gov.br/wps/content/Anvisa+Portal/Anvisa/Setor+Regulado/Como+Fazer/P orte+de+Empresas/Enquadramento+de+Porte+da+Empresa. Acesso em: 5 agosto 2013.

AKGÜN, A. E.; KESKIN, H.; BYRNE, J. The role of organizational emotional memory on declarative and procedural memory and firm innovativeness. Journal of Product Innovation Management, v. 29, n. 3, p. 432-451, 2012.

ALVARENGA NETO, R. C. D. Gestão do conhecimento em organizações: proposta de mapeamento conceitual interativo. São Paulo: Saraiva, 2008.

ALVESSON, M. De-essentializing the knowledge intensive firm: reflections on sceptical research going against the mainstream. Journal of Management Studies, v. 48, n. 7, p. 1640-1661, november 2011.

AMABILE, T. M. Creativity and innovation in organizations. Harvard Business Review, v. 5, n. 9, p. 1-15, 1996.

AMABILE, T. M. How to kill creativity. Harvard Business Review, v. 76, n. 5, p. 77-87, 1998.

AMABILE, T. M. et al. Assessing the work environment for creativity. The Academy of Management Journal, v. 39, n. 5, p. 1154-1184, 1996.

ARORA, A. S. The "organization" as an interdisciplinary learning zone: using a strategic game to integrate learning about supply chain management and advertising. The Learning Organization, v. 19, n. 2, p. 121-133, 2012. 
AUTANT-BERNARD, C. et al. Measuring the adoption of innovation: a typology of EU countries based on the Innovation Survey. Innovation: The European Journal of Social Science Research, v. 23, n. 3, p. 199-222, 2010.

AXELSSON, P.; SARDARI, N. A framework to assess organizational creative climate. Department of Technology Management and Economics. Göteborg: Chalmers University of Technology, p. 93. 2011.

BAKKER, A. B.; XANTHOPOULOU, D. Creativity and charisma among female leaders: the role of resources and work engagement. The International Journal of Human Resource Management, v. 24, n. 14, p. 2760-2779, 2013.

BEZERRA, C. A.; BARBOSA, S. R.; ESPEJO, M. M.D.S.B. Atividades de Gestão do Conhecimento entre organizações de assessoramento empresarial de naturezas distintas: um estudo em empresas no estado do Paraná. Perspectivas em Gestão \& Conhecimento, João Pessoa, v. 3, n. 2, p. 112-130, 2013.

BEZERRA, C. A.; GUIMARÃES, A. J.R. Mineração de texto aplicada às publicações científicas sobre gestão do conhecimento no período de 2003 a 2012. Perspectivas em Ciência da Informação, v. 19, n. 2, p. 131-146, 2014.

BHATT, G. D. Knowledge management in organizations: examining the interaction between technologies, techniques, and people. Journal of Knowledge Management, v. 5, n. 1, p. 68-75, 2001.

BORNAY-BARRACHINA, M. et al. Employment relationships and firm innovation: the double role of human capital. British Journal of Management, v. 23, p. 223-240, 2012.

BRASIL: MINISTÉRIO DO PLANEJAMENTO, ORÇAMENTO E GESTÃO. Manual de diagnóstico e elaboração de plano de Gestão do Conhecimento, baseado no Método de Avaliação do Conhecimento Organizacional (Organizational Knowledge Assessment Method - OKA). Brasília: MP: SLTI: CEGE: CT-GCIE, 2013.

BRATTSTROM, A.; LOFSTEN, H.; RICHTNÉR, A. Creativity, trust and systematic processes in product development. Research Policy, v. 41, n. 4, p. 743-755, 2012.

BROCKMAN, B. K.; JONES, M. A.; BECHERER, R. C. Customer orientation and performance in small firms: examining the moderating influence of risk-taking, innovativeness, and opportunity focus. Journal of Small Business Management, v. 50, n. 3, p. 429-446, 2012.

BUKOVITZ, W. R.; WILLIAMS, R. L. Manual de gestão do conhecimento. Porto Alegre: Bookman, 2002.

CABRAL, J. E.O. Determinantes da propensão para inovar e da intensidade inovativa em empresas da indústria de alimentos do Brasil. RAC, v. 11, n. 4, p. 87-108, 2007.

CAMELO-ORDAZ, C. et al. The influence of human resource management on knowledge sharing and innovation in Spain: the mediating role of affective commitment. The International Journal of Human Resource Management, v. 22, n. 7, p. 1442-1463, 2011.

CANIËLS, M. C.J.; RIETZSCHEL, E. F. Organizing creativity: creativity and innovation under constraints. Creativity and Innovation Management, v. 22, n. 1, p. 100-102, 2013.

CANTNER, U.; JOEL, K.; SCHMIDT, T. The use of knowledge management by German innovators. Journal of Knowledge Management, v. 13, n. 4, p. 187-203, 2009.

CARLSON, C. R.; WILMOT, W. W. Innovation: the five disciplines for creating what customers want. New York: Crown Business, 2006.

Perspectivas em Gestão \& Conhecimento, João Pessoa, v. 7, n. 1, p. 70-97, jan./jun. 2017. 
CARVALHO, H. Análise multivariada de dados qualitativos. 1. ed. Lisboa: Sílabo, 2008.

CARVALHO, H. G.; REIS, D. R.; CAVALCANTE, M. B. Gestão da inovação. Curitiba: Aymará Educação, 2011.

CEPEDA-CARRION, G.; CEgARRA-NAVARRO, J. G.; JIMENEZ-JIMENEZ, D. The effect of absorptive capacity on innovativeness: context and information systems capability as catalysts. British Journal of Management, v. 23, p. 110-129, 2012.

CERNE, M. et al. What goes around comes around: knowledge hiding, perceived motivational climate, and creativity. Academy of Management Journal, v. 57, n. 1, p. 172-192, 2014.

CERVANTES, V. H. Interpretaciones del coeficiente Alpha de Cronbach. Avances en Medición, v. 3, n. 1, p. 9-28, 2005.

CHADHA, S. K.; SAINI, R. Information technology support to knowledge management practices: a structural equation modeling approach. The IUP Journal of Knowledge Management, v. XII, n. 1, p. 39-52, 2014.

CHARTERINA, J.; LANDETA, J. Effects of knowledge-sharing routines and dyad-based investments on company innovation and performance: an empirical study of spanish manufacturing companies. International Journal of Management, v. 30, n. 1, p. 197-216, march 2013.

CHEDLI, M. K.E. Obtained resouces through individual networking inside the organization, creativity of the supervisor and innovation. Economics, Management \& Financial Markets, v. 9, n. 4, p. 376-394, 2014.

CHRISTOPHER, D.; TANWAR, A. Knowledge Management in outsourcing environment: people empowering people. The IUP Journal of Knowledge Management, v. X, n. 2, p. 61-86, 2012.

CHUA, R. Y.J. The costs of ambient cultural disharmony: indirect intercultural conflicts in social environment undermine creativity. Academy of Management Journal, v. 56, n. 6, p. 15451577, 2013.

CLAUß, T. The influence of the type of relationship on the generation of innovations in buyersupplier collaborations. Creativity and Innovation Management, v. 21, n. 4, p. 388-411, 2012.

COOPER, D. R.; SCHINDLER, P. S. Métodos de pesquisa em Administração. 7. ed. Porto Alegre: Bookman, 2003.

COSTA, L. F. et al. Disseminando práticas e saberes a partir da Ciência da Informação: relato de experiência do periódico Perspectivas em Gestão \& Conhecimento. XXV CONGRESSO BRASILEIRO DE BIBLIOTECONOMIA, DOCUMENTAÇÃO E CIÊNCIA DA INFORMAÇÃO, 25, 2013, Florianópolis. Anais... São Paulo: FEBAB, 2013. p. 1-10.

DABLA-NORRIS, E.; KERSTING, E. K.; VERDIER, G. Firm productivity, innovation, and financial development. Southern Economic Journal, v. 79, n. 2, p. 422-449, 2012.

DALKIR, K. Knowledge Management in theory and practice. Burlington, MA: Elsevier, 2005.

DAVENPORT, T. H. Ecologia da informação: por que só a tecnologia não basta para o sucesso na era da informação. São Paulo: Futura, 1998.

DAVILA, T.; EPSTEIN, M. J.; SHELTON, R. As regras da inovação. Porto Alegre: Bookman, 2007.

DE STOBBELEIR, K. E.M.; ASHFORD, S. J.; BUYENS, D. Self-regulation of creativity at work: the role of feedback-seeking behavior in creative performance. Academy of Management Journal, v. 54, n. 4, p. 811-831, 2011.

Perspectivas em Gestão \& Conhecimento, João Pessoa, v. 7, n. 1, p. 70-97, jan./jun. 2017. 
DENTI, L.; HEMLIN, S. Leadership and innovation in organizations: a systematic review of factors that mediate or moderate the relationship. International Journal of Innovation Management, v. 16, n. 3, p. 1-20, 2012.

DIBRELL, C.; CRAIG, J.; HANSEN, E. Natural environment, market orientation, and firm innovativeness: an organizational life cycle perspective. Journal of Small Business Management, v. 49, n. 3, p. 467-489, 2011.

DONG, S.; JOHAR, M. S.; KUMAR, R. L. A benchmarking model for management of knowledgeintensive service delivery networks. Journal of Management Information Systems, v. 28, n. 3, p. 127-160, 2012.

DOTZEL, T.; SHANKAR, V.; BERRY, L. L. Service innovativeness and firm value. Journal of Marketing Research, v. L, p. 259-276, 2013.

EL-MURAD, J.; WEST, D. C. The definition and measurement of creativity: what do we know? Journal of Advertising Research, v. 44, n. 2, p. 188-201, 2004.

EWING, M. T.; WEST, D. C. Advertising knowledge management: strategies and implications. International Journal of Advertising, v. 19, n. 2, p. 225-243, 2000.

FÁVERO, L. P.L. et al. Análise de dados. Rio de Janeiro: Elsevier, 2009.

FAVRETTO, V. Propaganda se prepara para alcançar R\$ 60 bi. Gazeta do Povo - Economia, 2012. Disponível em: http://www.gazetadopovo.com.br/economia/conteudo.phtml?id=1241575. Acesso em: 17 julho 2013.

FIALHO, J. M.R. Análise de redes sociais: princípios, linguagem e estratégias de ação na Gestão do Conhecimento. Perspectivas em Gestão \& Conhecimento, João Pessoa, v. 4, n. Número Especial, p. 9-26, outubro 2014.

FIBUCH, E.; VAN WAY III, C. W. What is a Knowledge Management System. and why should care? Physician Executive, v. 37, n. 5, p. 34-39, september-october 2011.

FIELD, A. Descobrindo a estatística usando o SPSS. 2. ed. Porto Alegre: Bookman, 2009.

FONSECA, A. F.; FRESNEDA, P. S.V. Manual de diagnóstico e elaboração de plano de gestão do conhecimento, baseado no Método de Avaliação do Comitê Técnico de Gestão do Conhecimento e da Informação Estratégica. Brasília: CT-GCIE, p. 94. 2013. (1.0).

GILSON, L. L. et al. Unpacking the cross-level effects of tenure diversity, explicit knowledge, and knowledge sharing on individual creativity. Journal of Occupational and Organizational Psychology, v. 86, n. 2, p. 203-222, 2013.

GOLD, A. H.; MALHOTRA, A.; SEGARS, A. H. Knowledge management: an organizational capabilities perspective. Journal of Management Information Systems, v. 18, n. 1, p. 185-241, 2001.

GONÇALO, J. A. et al. Creativity from constraint? How the political correctness norm influences creativity in mixed-sex work groups. Administrative Science Quarterly, v. 60, n. 1, p. 1-30, 2015.

GONG, Y. et al. A multilevel model of team goal orientation, information exchange, and creativity. Academy of Management Journal, v. 56, n. 3, p. 827-851, 2013. 
GONG, Y.; ZHOU, J.; CHANG, S. Core knowledge employee creativity and firm performance: the moderating role of riskiness orientation, firm size, and realized absorptive capacity. Personnel Psychology, v. 66, n. 2, p. 443-482, 2013.

GONZALEZ, R. V.D.; MARTINS, M. F. Um estudo teórico das características organizacionais que influenciam a gestão do conhecimento nas organizações. Perspectivas em Gestão \& Conhecimento, João Pessoa, v. 5, n. 2, p. 14-34, julho/dezembro 2015.

GUILFORD, J. P. Creativity. American Psychologist, v. 5, n. 9, p. 444-454, 1950.

HAIR JR, J. F. et al. Análise multivariada de dados. 5. ed. Porto Alegre: Bookman, 2005.

HARVEY, S. Creative synthesis: exploring the process of extraordinary group creativity. Academy of Management Review, v. 39, n. 3, p. 324-343, 2014.

HAWKINS, T. G.; NISSEN, M. E.; RENDON, R. G. Leveraging strategic sourcing and knowledge management to improve the acquisition of knowledge-based services. Journal of Public Procurement, v. 14, n. 2, p. 215-251, 2014.

HAYES, N.; WALSHAM, G. Knowledge sharing and ICTs: a relational perspective. In: EASTERBYSMITH, M.; LYLES, M. A. Handbook of organizational learning and knowledge management. Malden: Blackwell Publishing, 2005. Cap. 4, p. 54-77.

HIRST, G. et al. How does bureaucracy impact individual creativity? A cross-level investigation of team contextual influences on goal orientation-creativity relationships. Academy of Management Journal, v. 54, n. 3, p. 624-641, 2011.

IBOPE. Investimento publicitário - Praças 10 semestre 2014. Pesquisas de mídia, 2014. Disponível em: http://www.ibope.com.br/ptbr/conhecimento/TabelasMidia/investimentopublicitario/Paginas/PRA\%C3\%87AS---1\%C2\%BASEMESTRE-2014.aspx. Acesso em: 1 junho 2015.

IBRAHIM, F.; REID, V. Unpacking knowledge management: fad or real business practice? Enterprise Risk Management, v. 2, n. 1, p. 24-38, 2010.

IM, S.; MONTOYA, M. M.; WORKMAN JR, J. P. Antecedents and consequences of creativity in product innovation teams. Journal of Product Innovation Management, v. 30, n. 1, p. 170-185, 2013.

JASKYTE, K. et al. Transforming a nonprofit work environment for creativity: an application of concept mapping. Nonprofit Management \& Leadership, v. 21, n. 1, p. 77-92, 2010.

JENG, D. J.F.; DUNK, N. Knowledge management enablers and knowledge creation in ERP system success. International Journal of Electronic Business Management, v. 11, n. 1, p. 4959, 2013.

JIA, L. et al. A social-structural perspective on employee-organization relationships and team creativity. Academy of Management Journal, v. 57, n. 3, p. 869-891, 2014.

KIM, T. Y.; HON, A. H.Y.; LEE, D. H. Proactive personality and employee creativity: the fffects of job creativity requirement and supervisor support for creativity. Creativity Research Journal, v. 22, n. 1, p. 37-45, 2010.

LASAGNI, A. How can external relationships enhance innovation in SMEs? New evidence for Europe. Journal of Small Business Management, v. 52, n. 2, p. 310-339, 2012. 
LOMBARDO, R.; BEH, E. J. Simple and multiple correspondence analysis for ordinal-scale variables using orthogonal polynomials. Journal of Applied Statistics, v. 37, n. 12, p. 21012116, 2010.

MAGESWARI, S. D.U.; SIVASUBRAMANIAN, C.; DATH, T. N.S. Knowledge management enablers, processes and innovation in small manufacturing firms: a structural equation modeling approach. The IUP Journal of Knowledge Management, v. XIII, n. 1, p. 33-58, 2015.

MAROCO, J.; GARCIA-MARQUES, T. Qual a fiabilidade do alfa de Cronbach? Questões antigas e soluções modernas? Laboratório de Psicologia, v. 4, n. 1, p. 65-90, 2006.

MATHISEN, G. E.; EINARSEN, S. A review of instruments assessing creative and innovative environments within organizations. Creativity Research Journal, v. 16, n. 1, p. 119-140, 2004.

MCFADDEN, K. L. et al. Linking quality improvement practices to knowledge management capabilities. Quality Management Journal, v. 21, n. 1, p. 42-58, 2014.

MCIVER, D. et al. Understanding work and knowledge management from a knowledge-inpractice perspective. Academy of Management Review, v. 38, n. 4, p. 597-620, 2013.

MIERES, C. G.; SÁNCHEZ, J. Á.L.; VIJANDE, M. L.S. Internal marketing, innovation and performance in business services firms: the role of organizational unlearning. International Journal of Management, v. 29, n. 4, p. 403-429, 2012.

MOHANTY, K.; KAR, S. Achieving innovation and success: organizational learning. SCMS Journal of Indian Management, v. 9, n. 1, p. 36-42, 2012.

NAILA, A. et al. D-learning model for knowledge management in enterprise 2.0. International Journal of Advanced Corporate Learning, v. 7, n. 1, p. 5-10, 2014.

NANDITA, S. Improving organization performance through Knowledge Management practices. Advances in Management, v. 6, n. 2, p. 56-60, 2013.

NONAKA, I.; KONNO, N. The concept of "Ba": building a foundation for knowledge creation. California Management Review, v. 40, n. 3, p. 40-55, 1998.

NONAKA, I.; TAKEUCHI, H. Criação de conhecimento na empresa. Rio de Janeiro: Campus, 1997.

OKE, A.; WALUMBWA, F. O.; MYERS, A. Innovation strategy, human resource policy, and firms' revenue growth: the roles of environmental uncertainty and innovation performance. Decision Sciences, v. 43, n. 2, p. 273-302, 2012.

PAN, W.; SUN, L. Y.; CHOW, I. H.S. Leader-member exchange and employee creativity: test of a multilevel moderated mediation model. Human Performance, v. 25, n. 5, p. 432-451, 2012.

PRADO, J. C.A.; FISCHER, A. L. Condiciones de la gestión del conocimiento, capacidad de innovación y resultados empresariales: un modelo explicativo. Pensamiento \& Gestión, Barranquilla, v. 37, p. 25-63, 2013.

PRESTER, J.; BOZAC, M. G. Are innovative organizational concepts enough for fostering innovation? International Journal of Innovation Management, v. 16, n. 1, p. 23, 2012.

PUGNA, I. B.; BOLDEANU, D. M. Factors affecting establishment of an institutional knowledge management culture - a study of organizational vision. Accounting and Management Information Systems, v. 13, n. 3, p. 559-583, 2014. 
QUANDT, C. O.; BEZERRA, C. A.; FERRARESI, A. A. Dimensões da inovatividade organizacional e seu impacto no desempenho inovador: proposição e avaliação de um modelo. Gestão \& Produção, São Carlos, v. 22, n. 4, p. 873-886, out/dez 2015.

RAO, B. C. How to measure innovation. Challenge, v. 53, n. 1, p. 109-125, 2010.

REJEB, H. B. et al. Measuring innovation best practices: improvement of an innovation index integrating threshold and synergy effects. Technovation, v. 28, p. 838-854, 2008.

REMNELAND-WIKHAMN, B.; WIKHAMN, W. Open innovation climate measure: the introduction of a validated scale. Creativity and Innovation Management, v. 20, n. 4, p. 284295, 2011.

ROGERS, E. M. Diffusion of innovations. 3. ed. New York: The Free Press, 1983.

ROMEIRO, A. A.; WOOD JR, T. Creativity: understanding the restrictions on creative work in advertising agencies. Brazilian Administration Review, Rio de Janeiro, v. 12, n. 1, p. 1-21, 2015.

ROSELLO, J.; TRAN, V. Assessing the climate for creativity: the example of a french high-tech organization. 12TH EUROPEAN CONFERENCE ON CREATIVITY AND INNOVATION, 12, 2011, Faro. Proceedings... Faro: EACl, 2011. p. 581-596.

RUBERA, G.; KIRCA, A. H. Firm innovativeness and its performance outcomes: a meta-analytic review and theoretical integration. Journal of Marketing, v. 76, p. 130-147, 2012.

SAEGER, M. M.M.T. Da informação à auditoria de conhecimento: a base para a inteligência organizacional. Perspectivas em Gestão \& Conhecimento, João Pessoa, v. 6, n. 1, p. 270-274, janeiro/junho 2016.

SAGIV, L. et al. Structure and freedom in creativity: the interplay between externally imposed structure and personal cognitive style. Journal of Organizational Behavior, v. 31, n. 8, p. 10861110, 2010.

SAINI, R. Model development for key enablers in the implementation of Knowledge Management. The IUP Journal of Knowledge Management, v. XI, n. 2, p. 46-62, 2013.

SANTHOSHKUMAR, R.; RAJASEKAR, N. Talent measure sculpt for effective talent management: a practical revise. The IUP Journal of Management Research, v. XI, n. 1, p. 38-47, 2012.

SCHUMPETER, J. A. The theory of economic development. Cambridge: Transaction Books, 1934.

SHEU, D. D.; LEE, H.-K. A proposed process for systematic innovation. International Journal of Production Research, v. 49, n. 3, p. 847-868, 2011.

SHOLLA, A.; NAZARI, E. Knowledge management and factors that influence the success of codification strategies in medium-sized companies that develop software: the model, strategies and tools. Journal of Information Technology and Economic Development, v. 2, n. 1, p. 54-63, april 2011.

SOHN, S. Y.; JUNG, C. S. Effect of creativity on innovation: do creativity initiatives have significant impact on innovative performance in korean firms? Creativity Research Journal, $v$. 22, n. 3, p. 320-328, 2010.

STAL, E. Inovação tecnológica, sistemas nacionais de inovação e estímulos organizacionais à inovação. In: MOREIRA, D. A.; QUEIROZ, A. C.S. Inovação organizacional e tecnológica. São Paulo: Thomson Learning, 2007.

Perspectivas em Gestão \& Conhecimento, João Pessoa, v. 7, n. 1, p. 70-97, jan./jun. 2017. 
SURIYAMURTHI, S.; VELAVAN, M.; RADHIGA, T. D. Importance of leadership in innovations of HR practices. Advances in Management, v. 6, n. 11, p. 47-54, 2013.

SVEIBY, K. E. A nova riqueza das organizações: gerenciando e avaliando patrimônios do conhecimento. Rio de Janeiro: Campus, 1998.

SVEIBY, K. E. Knowledge Management: lessons learned from the KM pioneers. Sveiby Knowledge Associates, 2001. Disponível em: www.sveiby.com/articles/index.html. Acesso em: 19 outubro 2016.

TAKEUCHI, H.; NONAKA, I. Gestão do conhecimento. Porto Alegre: Bookman, 2008.

TARSITANO, P. R. Publicidade brasileira: mudanças para continuar sendo forte. Revista Latinoamericana de Ciencias de la Comunicación, São Paulo, v. 5, n. 8-9, p. 176-189, 2008.

TAYLOR, G. Implementing and maintaining a knowledge sharing culture via knowledge management teams: a shared leadership approach. Journal of Organizational Culture, Communications and Conflict, v. 11, n. 1, p. 69-91, 2013.

TSAUR, S. H.; YEN, C. H.; YANG, W. Y. Do job characteristics lead to employee creativity in travel agencies? International Journal of Tourism Research, v. 13, n. 2, p. 191-204, 2011.

UZKURT, C. et al. The impact of environmental uncertainty dimensions on organisational innovativeness. International Journal of Innovation Management, v. 16, n. 2, p. 23, 2012.

VACARO, I. G. et al. Management innovation and leadership: the moderating role of organizational size. Journal of Management Studies, v. 49, n. 1, p. 28-51, 2012.

VARELA, A. V.; BARBOSA, M. L.A.; FARIAS, M. G.G. Abordagem cognitiva para gestão do planejamento estratégico nas organizações. Perspectivas em Gestão \& Conhecimento, João Pessoa, v. 5, n. 2, p. 49-68, julho/dezembro 2015.

VON KROGH, G.; NONAKA, I.; RECHSTEINER, L. Leadership in organizational knowledge creation: a review and framework. Journal of Management Studies, v. 49, n. 1, p. 240-277, 2012.

WANG, A. C.; CHENG, B. S. When does benevolent leadership lead to creativity? The moderating role of creative role identity and job autonomy. Journal of Organizational Behavior, v. 31, n. 8, p. 1086-1110, 2010.

WANG, K. Factors influencing the adoption and effective use of creativity techniques in business settings: an exploratory study. Engineering Management Journal, v. 26, n. 4, p. 2937, 2014.

WEST, M. A.; FARR, J. L. Innovation at work. In: WEST, M. A.; FARR, J. L. Innovation and creativity at work: psychological and organizational strategy. Chichester: Willey-Blackwell, 1990. p. 349.

WIIG, K. M. Knowledge management: an introduction and perspective. Journal of Knowledge Management, v. 1, n. 1, p. 6-14, 1997.

WILLERDING, I. A.V.; KRAUSE, M. G.; LAPOLLI, É. M. Gestão de pessoas e gestão do conhecimento à luz da estética organizacional em uma organização de base tecnológica. Perspectivas em Gestão \& Conhecimento, João Pessoa, v. 6, n. 1, p. 141-154, janeiro/junho 2016.

ZENITHOPTIMEDIA. Executive summary: advertising expenditure forecasts april 2013. ZenithOptimedia The ROI Agency, 2013. Disponível em: 
http://www.zenithoptimedia.com/wp-content/uploads/2013/04/ZO-Adspend-Forecast-April2013-executive-summary.pdf. Acesso em: 19 julho 2013.

ZHANG, X.; BARTOL, K. M. Linking empowerment leadership and employee creativity: the influence of psychological empowerment, intrinsic motivation, and creative process engagement. Academy of Management Journal, v. 53, n. 1, p. 107-128, 2010. 